\begin{abstract}
Title of Document:

EFFECTS OF SUGAR SOLUTIONS ON HYPOTHALAMIC APPETITE REGULATION

Danielle Louise Colley, Master of Science, 2013

Directed By:

Professor Thomas W. Castonguay

Department of Nutrition and Food Science
\end{abstract}

There are multiple hypotheses for the causes of the obesity epidemic. One such hypothesis is that dietary intake patterns have significantly shifted to include unprecedented amounts of refined sugar. We set out to determine some the unique metabolic changes that occur with initial exposure to dilute glucose, sucrose, high fructose corn syrup, or fructose solutions. Rats were given access to food, water and a sugar solution for $24 \mathrm{~h}$, after which blood and tissues were collected. Fructose access (as opposed to other sugars investigated) resulted in a doubling of circulating triglycerides. Glucose consumption resulted in upregulation of 7 satiety related hypothalamic peptides whereas changes in gene expression were mixed for remaining sugars. Also, following multiple verification assays, 6 satiety related peptides were verified as being affected by sugar intake. These data provide evidence that not all sugars are equally effective in affecting the control of intake. 


\title{
EFFECTS OF SUGAR SOLUTIONS ON HYPOTHALAMIC APPETITE REGULATION
}

\author{
By \\ Danielle Louise Colley
}

Thesis submitted to the Faculty of the Graduate School of the University of Maryland, College Park, in partial fulfillment of the requirements for the degree of

Master of Science

2013

Advisory Committee:

Professor Thomas W. Castonguay, Chair

Arthur N. Popper

Y. Martin Lo 
(C) Copyright by

Danielle Louise Colley

2013 


\section{Acknowledgements}

Thank you to the love of my life Bob for all the compassion, support and understanding. Without you, I wouldn't have made it. You are my greatest cheerleader. I love you.

To Dr. C, thank you for being the world's greatest advisor! You have taught me so much I am so thankful for the impact you have made on my life. Thank you for EVERYTHING! "Stay the course." 


\section{Table of Contents}

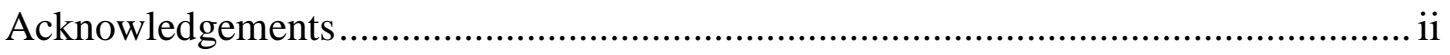

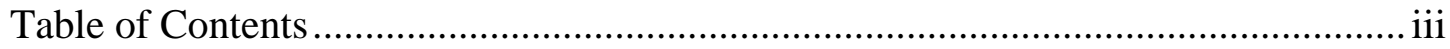

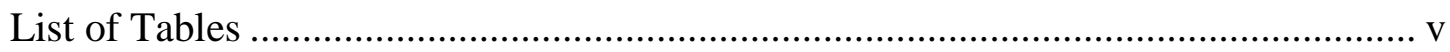

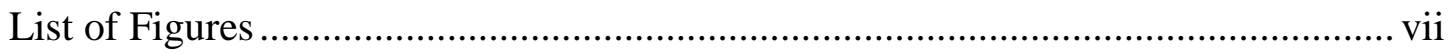

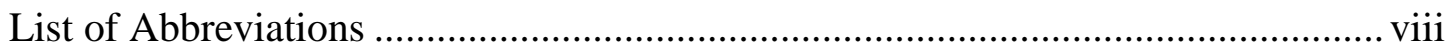

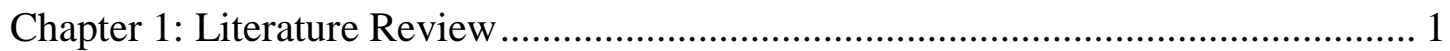

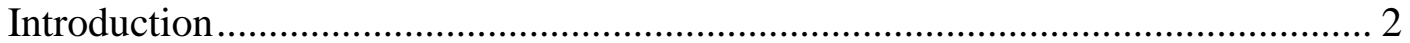

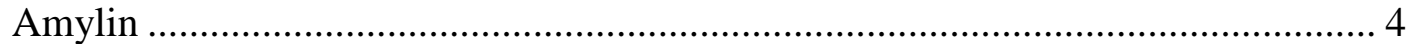

Agouti Related Peptide ............................................................................. 5

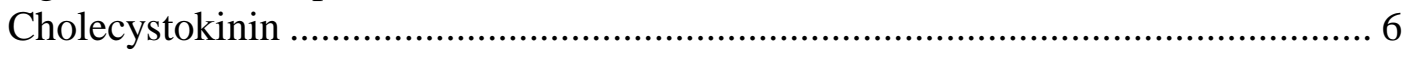

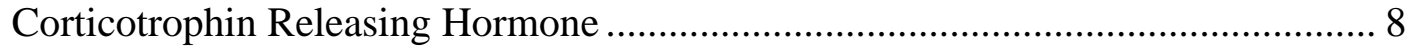

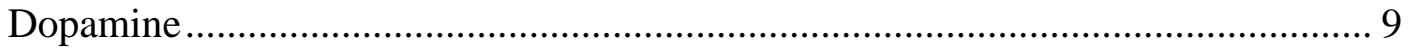

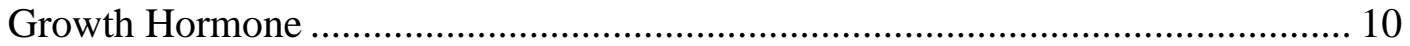

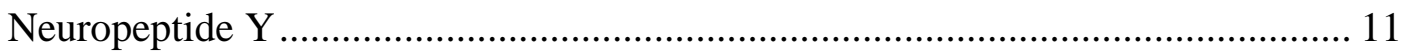

Receptor Activity Modifying Protein 3 ........................................................ 12

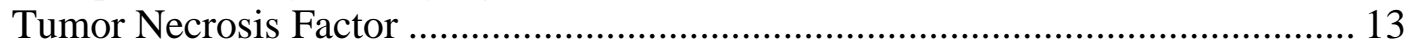

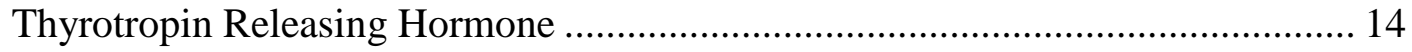

Chapter 2: Effects of Sugar Solutions on Hypothalamic Appetite Regulation........... 15

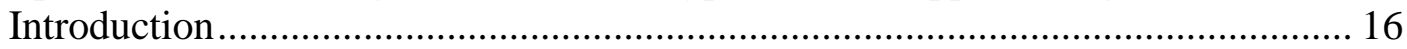

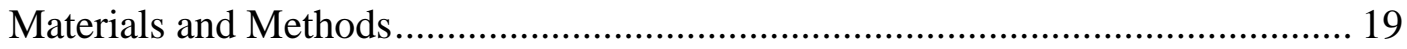

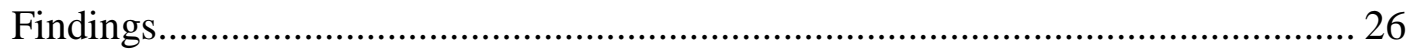

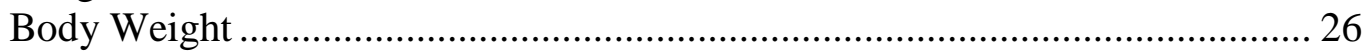

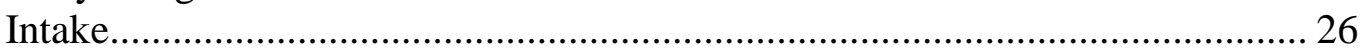

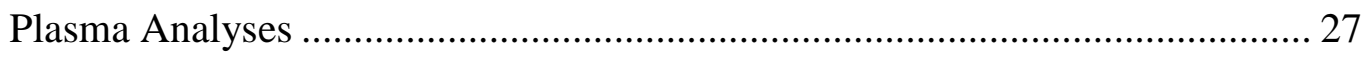

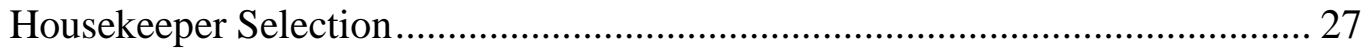

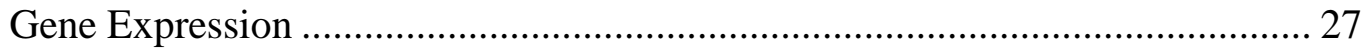

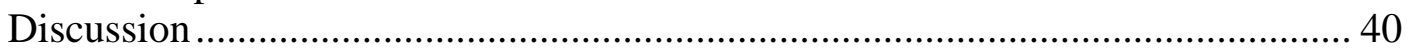

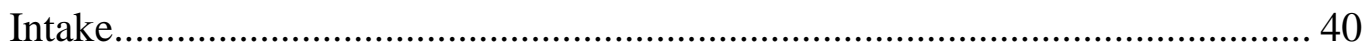

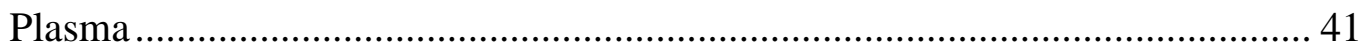

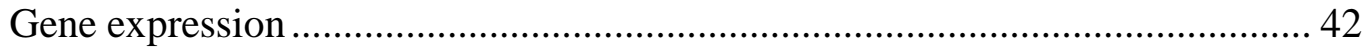

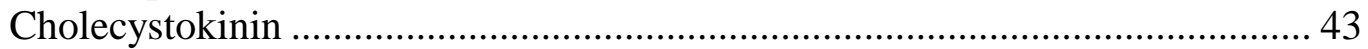

Corticotrophin Releasing Hormone .......................................................... 44

Growth Hormone .............................................................................. 45

Receptor Activity Modifying Protein 3 .................................................... 46

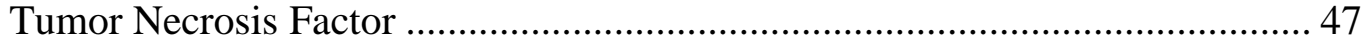

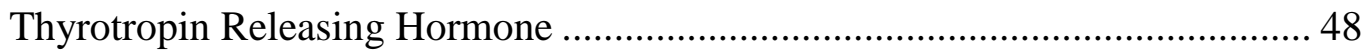

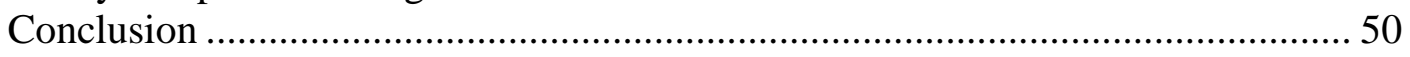




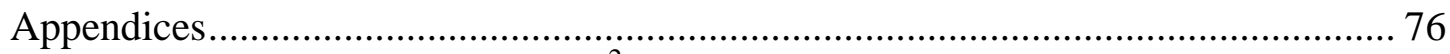

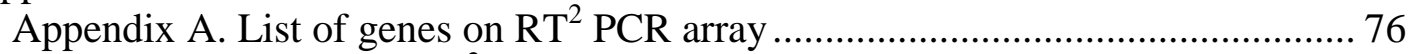

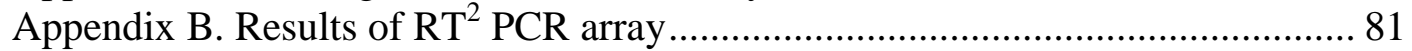

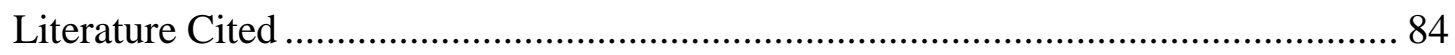




\section{List of Tables}

Table 1. Primers used for pooled and individual verification RT-PCR analyses....... 55

Table 2. Average body weight of rats following 24 hour sugar access ....................... 56

Table 3. Mean chow and sugar intake following 24 hour access to sugar solutions .. 57

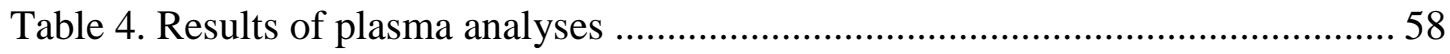

Table 5. Cycle threshold $(\mathrm{Ct})$ of housekeepers ..............................................................5 59

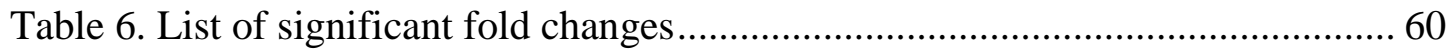

Table 7. Summary of analysis used to determine the effect of sugar solution access on

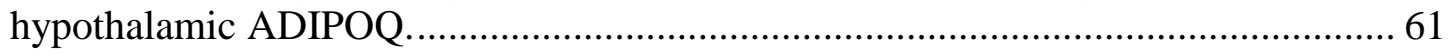

Table 8. Summary of analyses used to determine the effect of sugar solution access

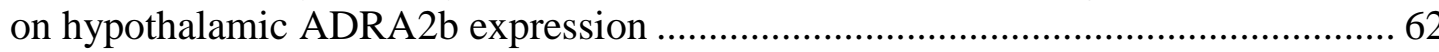

Table 9. Summary of the three analyses used to determine the effect of sugar solution

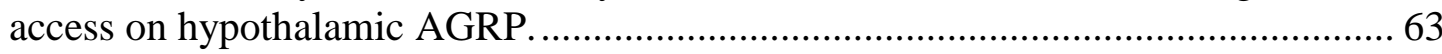

Table 10. Summary of analysis used to determine the effect of sugar solution access on hypothalamic APOA4.

Table 11. Summary of the three analyses used to determine the effect of sugar solution access on hypothalamic CCK.

Table 12. Summary of analysis used to determine the effect of sugar solution access on hypothalamic CLPS.

Table 13. Summary of analyses used to determine the effect of sugar solution access on hypothalamic CRH.

Table 14. Summary of the three analyses used to determine the effect of sugar solution access on hypothalamic DRD1a. 68

Table 15. Summary of the three analyses used to determine the effect of sugar solution access on hypothalamic GH1.

Table 16. Summary of analyses used to determine the effect of sugar solution access on hypothalamic IAPP.

Table 17. Summary of the three analyses used to determine the effect of sugar solution access on hypothalamic NPY. 
Table 18. Summary of the three analyses used to determine the effect of sugar solution access on hypothalamic RAMP3.

Table 19. Summary of analyses used to determine the effect of sugar solution access on hypothalamic TNF- $\alpha$.

Table 20. Summary of analyses used to determine the effect of sugar solution access on hypothalamic TRH.

Table 21. Summary of analyses used to determine the effect of sugar solution access on hypothalamic UCN. 


\section{List of Figures}

Figure 1. Relationship between fructose intake and prevalence of overweight and

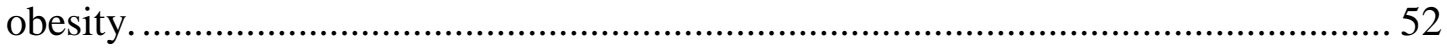

Figure 2. Metabolism of glucose and fructose ........................................................... 53

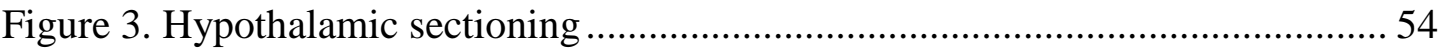




\section{List of Abbreviations}

ACTH Adrenocorticotropic hormone

ADIPOQ

Adiponectin

ADRA2b

Adrenergic, alpha-2B-, receptor

ADX.

Adrenalectomized

AGRP

Agouti-related peptide

ANOVA

Analysis of variance

AP

Area postrema

APOA4

Apolipoprotein A-IV

ARC

Arcuate nucleus

BP

Base pair

CCK

Cholecystokinin

Cdna . Complementary DNA

$\mathrm{CHO}$ Carbohydrate

CLPS

Colipase, pancreatic

CLR Calcitonin receptor-like receptor

$\mathrm{CNS}$ Central nervous system

CRH/CRF Corticotropin-releasing hormone/factor CSF Cerebral spinal fluid

$\mathrm{Ct}$ Threshold Cycle

DRD1a Dopamine receptor D1A GAPDH Glyceraldehyde 3-phosphate dehydrogenase

$\mathrm{GH}$ Growth hormone 
GHS-R Growth hormone secretagogue receptor GPCR G protein-coupled receptor HFCS High fructose corn syrup IAPP Islet amyloid polypeptide, Amylin Il1a Interleukin 1 alpha

Il6 Interleukin 6 INS2 Insulin 2

IV Intravenous

$\mathrm{KO}$ Knock out LDHA Lactate dehydrogenase A $\mathrm{MCH}$ Melanin-concentrating hormone mRNA Messenger ribonucleic acid MSH Melanocyte-stimulating hormone NAC Nucleus accumbens NMU Neuromedin U NPY. Neuropeptide Y NTRK1 Neurotrophic tyrosine kinase, receptor, 1 NTS Nucleus tractus solitarius PCR Polymerase chain reaction POMC Pro-opiomelanocortin PPG Preproglucagon PVN. Periventricular nucleus RAMP2 Receptor activity modifying protein 2 
RAMP3 Receptor activity modifying protein 3

RPLP1 Ribosomal protein, large, $\mathrm{P} 1$

RNA Ribonucleic acid RT-PCR Real time polymerase chain reaction Ta Annealing temperature

TaOpt Optimum annealing temperature TCA. Tricarboxylic acid TG Triglyceride

TNF Tumor necrosis factor TRH/TRF Thyrotropin- releasing hormone/factor $\mathrm{UCN}$ Urocortin 
Chapter 1: Literature Review 


\section{Introduction}

Despite years of research, and millions of dollars spent every year in prevention and treatment, obesity has become the nation's most preventable health problem $(1,2)$. The current obesity epidemic is not attributable to any one factor, and is not restricted by race, nationality, age or gender (3). Despite its prevalence, there is no known cure for this disease. Several hypotheses about how obesity develops have been proposed that help guide research efforts.

One such hypothesis is that dietary patterns of Americans have significantly shifted over the past fifty years by including unprecedented amounts of refined sugar (4). Others have added that not all sugars are the same, and that fructose in particular accounts for much of the increase in sugar intake in the American diet $(5,6)$. From 1970 to 1990 , consumption of high fructose corn syrup (HFCS) increased more than $1000 \%$ and currently accounts for $40 \%$ of all added caloric sweeteners $(7,8)$.

Evidence that fructose is capable of promoting excessive weight gain has been reported in animal models and in humans. Figure 1 depicts the trends of overweight and obesity with the increase in fructose consumption in the US over the years. Rats maintained on a diet rich in HFCS for 6 or 7 months show abnormal weight gain, increased circulating triglycerides (TG) and augmented fat deposition (9). This hypothesis is not without its critics. Several groups have reported that when tested side-by-side, fructose is no more or less effective in promoting excess weight gain $(10,11)$.

It has long been established that the hypothalamus, particularly the arcuate nucleus, is the center of appetite regulation in the brain (12). Many researchers have 
examined the role of peripheral hunger and satiety messages. However in the past 15 years exploration of the connection of the CNS to energy homeostasis has accelerated (13). This increase is due to increases in scientific technology including genetic assays as well as improvements in the study of neuroscience. In the past, ablation studies were the fundamental method for understanding how changes in the brain affect energy balance. In fact, these ablation studies are how it was originally established the hypothalamus is so important for appetite regulation (14).

For the purpose of this review, literature pertaining to appetite regulatory genes of the hypothalamus, particularly those impacted by sugar consumption, will be considered. Of course there are probably hundreds of genes in the hypothalamus that relate to energy balance in one form or another. Therefore, genes included in this review were selected based upon recommendations from the manufacturer of an obesity related PCR array that has been used in our laboratory (SABioscience, Frederick, MD). The PCR system used for this analysis was a rat obesity $\mathrm{RT}^{2}$ ProfilerTM PCR Array (PARN-017A). A PCR array is a multi-well plate that has been pre-loaded with specified primer pairs, in this case primers for genes relating to obesity. RNA and PCR reagents are added to the plate and using a thermal cycler, quantitative changes in gene expression are measured. The benefit of this system is it allows for analysis of multiple genes in a single experiment in a very short time. For the purpose of this study, gene expression in hypothalamic tissue of rats given 24 hour access to either glucose, sucrose, HFCS, or fructose was examined. From these data 'significant' changes in gene expression were identified. From that list the most 
'significant' and interesting changes in gene expression were selected for inclusion in this review.

\section{Amylin}

Amylin, also known as Islet Amyloid Polypeptide (IAPP), is a 37 amino acid peptide hormone. Amylin reduces eating via meal size effect by promoting meal ending satiation. In the periphery it has been observed that amylin reduces gastric acid secretion, slows gastric emptying, and reduces pancreatic glucagon secretion (15). Pancreatic $\beta$-cells are the major source of circulating amylin and it is generally believed that the role of amylin in appetite regulation is as a result of secretion from $\beta$-cells (16).

Amylin acts centrally via action in the area postrema (AP), which is rich in amylin receptors. The presence of amylin synthesized centrally is still highly debated. According to Lutz (2011), there is currently no evidence for central amylin synthesis (17). One possible reason that amylin synthesis has not been identified centrally may be in part due to the fact that most studies thus far have focused on male rats.

Dobolyi and colleagues have reported that IAPP was upregulated in the preoptic area of the hypothalamus in the early postpartum period. Utilizing micro array technology, RT-PCR and in situ hybridization for verification, amylin expression was found to be significantly increased in dams and mothers whose pups were removed immediately after delivery. These findings suggest that in female rats, central amylin synthesis may be important for maternal regulatory mechanisms (18). 


\section{Agouti Related Peptide}

Agouti-related protein (AGRP) is a 132 amino acid obesogenic peptide produced in the ventromedial portion of the arcuate nucleus in the hypothalamus. AGRP and neuropeptide Y (NPY) are co-expressed and both are produced in AGRP/NPY neurons. AGRP is one of the most potent and long-lasting of appetite stimulators.

Release of AGRP and NPY from AGRP/NPY neurons is inhibited by insulin. By inactivating the insulin receptor on AGRP neurons, Konner and colleagues found that insulin failed to regulate hepatic glucose production (19). This result demonstrates the importance of AGRP in insulin-induced suppression of hepatic glucose production. These findings suggest that AGRP may be a new target for type 2 diabetes therapies.

Given that AGRP and NPY are involved in insulin regulation, it is not surprising that they are activated by sugar intake. Sucrose intake causes direct changes in NPY and AGRP expression in the ARC. Following a sucrose preload, AGRP and NPY mRNA expression was suppressed for the first 10 min following preload. During this interval there was also in increase in plasma and CSF glucose. In the subsequent interval (30-60 min) AGRP and NPY mRNA expression then increased (20).

Sucrose preloads increased intake in the subsequent meal as compared to a starch preload. Leibowitz and colleagues have suggested that sucrose causes increased intake and hunger following intake due to increased expression of orexogenic peptides NPY and AGRP (21). Gaysinskaya also suggests that NPY and 
AGRP's orexegenic mechanisms are directed toward increased consumption of $\mathrm{CHO}$ where as other orexogenic peptides may act to increase intake of fats (20).

\section{Cholecystokinin}

Cholecystokinin (CCK) is an anorexogenic peptide that is expressed in both the small intestine and the brain. CCK was discovered in 1928 in a study examining the ability of intestinal extracts to stimulate gallbladder contraction in dogs. However, CCK was not purified and sequenced until 1966 by Jorpes and Mutt (22). CCK comes in many forms, denoted by size. For example, CCK-33, which was the first to be discovered, is a 33-amino acid peptide. The most common CCK form is CCK-8, which is an 8 amino acid peptide. All forms of CCK are derived from the same $C C K$ gene by post translational or extracellular processing. Expression of CCK results in short duration reduction of meal size (23).

Despite much of the literature surrounding CCK being focused on its expression in the gut, $\mathrm{CCK}$ is one of the must abundantly expressed peptides in the brain (24). In the brain, CCK is expressed in the cerebellum, cortex, midbrain, hypothalamus and hippocampus (25).

Woods et al have theorized that CCK has two roles in satiation. First, CCK signals a reduction in meal size and second, CCK acts as a mediator of the satiation process (13). CCK is a mediator of the satiation process via many mechanisms including increasing hypothalamic permeability to leptin (26). Leptin is a signal for overall body adiposity status and CCK is a gatekeeper for this message entering the hypothalamic area (26). 
It has been suggested that obesity, as a result of leptin resistance, may be due to impaired transport of leptin from the blood into the CNS (26). Rats that lack the CCK1 receptor are resistant to peripheral leptin but not leptin directly infused into the brain. To explore the connection between CCK and leptin, Cano et al administered leptin in the periphery to animals that had been given a CCK-1 receptor antagonist. They found that although leptin gradually decreased in the plasma, it simultaneous increased in concentration in the CSF (26). This finding suggests that leptin builds up in the periphery when CCK is blocked. Thus CCK increases leptin permeability into the CNS.

Insulin, in its role as another adiposity signal, is also linked to CCK expression. Lo (2011) using CCK-KO mice, found that when maintained on a low-fat diet animals had a reduced acute insulin response to glucose (27). However, when maintained on a high fat diet, CCK-KO mice developed glucose intolerance. The importance of this finding is it shows that $\mathrm{CCK}$ is required for regulating both insulin secretion and glucose tolerance in mice on a high fat diet.

Hisadome and colleagues found that an important role of CCK is to regulate neuronal circuitry (28). The aim of their study was to investigate the circuitry which links CCK to nucleus tractus solitarius- preproglucagon (NTS-PPG) neurons. PPG neurons express Glucagon-like peptide-1 which acts to modulate gastric emptying, glucose homeostasis, and appetite control. The researchers found that CCK does modulate the activity of PPG neurons however does so indirectly by acting through adrenergic neurons. 


\section{Corticotrophin Releasing Hormone}

Corticotropin-releasing hormone (CRH), also known as Corticotropinreleasing factor $(\mathrm{CRF})$ is a 41 -amino acid anorectic peptide. CRF was first identified by Vale in 1981 (29). CRH is secreted by neurosecretory cells of the parvocellular region of the periventricular nucleus $(\mathrm{PVN})$ of the hypothalamus and carried via the portal system to the anterior lobe of the pituitary where it promotes ACTH production (30). There are few studies relating CRH to diet and circulating nutrients. CRH has been found to have little response to increases in fat intake (21). Widmaier found that when glucose was removed from an extracted section of rat hypothalamus, there was in increase in CRF production that could be reversed by adding back glucose (31). This increase in CRF as a response to a lack of glucose may be to stimulate glucocorticoid release. Jang and colleagues found that in rats lacking glucocorticoids (via adrenalectomy), leptin administration rapidly increased CRH secretion (and decreased NPY secretion) (32).

Given the connection between CRF and glucose, it is no surprise that there is also a connection between $\mathrm{CRH}$ and insulin. When leptin is centrally injected, CRH mRNA expression in the PVN is increased. However, the opposite effect is observed when glucocorticoids are administered (32). This finding suggests that interactions between leptin and glucocorticoids regulate $\mathrm{CRH}$.

The effect of sucrose on CRF expression has also been evaluated. Daily limited access to a sucrose sweetened drink resulted in decreased CRH mRNA expression (33). When adrenalectomized (ADX) rats were allowed to consume sucrose sweetened drinks, they experience normal weight gain and food intake and 
have normal CRF levels throughout the brain (34). This finding suggests that CRF may be produced due to a drop in glucose in order to maintain levels of glucocorticoids.

\section{Dopamine}

Dopamine is catecholamine (biogenic amine) synthesized from tyrosine. Both are derived. All three catecholamines in this pathway (norepinephrine, epinephrine, and dopamine) function as neurotransmitters. Dopamine is released from the nucleus accumbens and the dorsal striatum in response to intake of palatable foods such as sugar (35). The hypothalamus has also been cited as a site of dopamine action in response to sucrose intake (36-39). Though dopamine has many actions in the brain, actions relating to intake will be the focus of this review.

Dopamine is probably not directly involved in huger and satiety mechanisms but rather influences food intake via reward mechanisms. When palatable foods are consumed, reward pathways, including the nigrostriatal dopaminergic pathway, are activated (40). Foods that are high in sugar and fat are known to activate the reward system and promote eating and prompt conditioning (41). Dopamine antagonists will attenuate this response and supress intake of sweets in rats (40, 42-44).

Overeating obesogenic diets blunts the dopamine signalling pathway. Increased consumption of sugars compensates for this blunted reward pathway (43). Pritchett and colleagues induced obesity in rats with a high fat/high $\mathrm{CHO}$ diet. Rats were given dopamine receptor antagonists IV. They found that lean animals 
consumed less sugar solution then obese and thus obese animals had reduced dopamine receptor signalling (43).

Genetic differences in the dopamine gene have been shown to result in differences in acquisition of sugar preference. Dym et al. found that genetic differences between standard breeds of mice result in differences in the expression of the learned sucrose preference phenotype (45). Dym has attributed this to be a result of polymorphisms of taste receptors. Other researchers have found that newly discovered taste receptors in the gut may trigger dopamine responses upon exposure to sucrose (46). Similar reports of the impact of sugar on dopamine release have been reported by both Hoebel and Smith. Hoebel postulated that there may a connection with excessive sucrose intake and changes in the dopaminergic pathway in the hypothalamus (36). Smith and colleagues also reported similar conclusionshypothalamic dopamine plays an integral role in the control of sucrose intake (37-39).

\section{Growth Hormone}

Growth hormone $(\mathrm{GH})$ is a 191 amino acid long hormone. $\mathrm{GH}$ is released by the lateral wings of the anterior pituitary gland and regulated by neurosecretory nuclei of the hypothalamus. The GHI gene encodes the protein somatotropin. $\mathrm{GH}$ is thought to be an anorexogenic peptide that not only contributes to the regulation of energy expenditure but also growth. However, there is limited literature surrounding the effects of Growth Hormone (GH) on the regulation of energy balance and intake. Much of the literature surrounding GH is centered around the effects of ghrelin on GH modulation. Ghrelin is a potent orexogenic hormone that functions, in part, to 
stimulate the release of $\mathrm{GH}$ via binding to growth hormone secretagogue receptor (GHS-R) $(47,48)$.

Several reports of the effects of GH on fasted or food limited animals have been published. During fasting and anorexia, insulin is suppressed and GH is elevated. The reason behind this elevation is thought to be due to $\mathrm{GH}$ antagonizing the actions of insulin so as to promote lipolysis and lipid oxidation (49). Gahete and colleagues examined this connection using female adult onset, isolated GH-deficient mice. These animals showed increased fat depot weight as compared to controls. This suggests that the importance of GH during fasting is more for the support of fat mobilization for gluconeogenesis and muscle function rather than for the maintenance of glucose levels (50).

Strauch and colleagues examined the effects of fructose on plasma GH levels in humans (51). They reported that in humans fructose, when administered IV at a dosage between 0.3 and $0.5 \mathrm{~g} / \mathrm{kg}$, is a potent stimulator of $\mathrm{GH}$ secretion. These results were in contrast to previous reports surrounding the effects of glucose on GH which suggested that glucose suppressed GH secretion.

\section{Neuropeptide $\mathbf{Y}$}

Neuropeptide Y (NPY) is a 36 amino acid, obesogenic peptide that also acts as a neurotransmitter in the arcuate nucleus of hypothalamus. NPY is co-localized on neurons with AGRP (Agouti-related peptide). NPY has a dramatic effect on stimulating feeding (52). NPY/AGRP neurons inhibited (depolarized) by increased 
levels of both insulin and leptin (53-55). When insulin and leptin levels in the plasma are low, NPY/AGRP expression is increased $(32,56)$.

There has also been extensive work done to evaluate the effects of carbohydrates on NPY expression. There is a strong NPY expression peak at the start of the natural feeding period that is thought to support the utilization of carbohydrate (21). In 1988, Rowland reported that animals given injections of NPY into the PVN

there is a robust increase in feeding. This affect is then attenuated when an IV dose of glucose is given. The attenuation however does not occur when a dose of fructose is administered (57). This finding demonstrates that these two monosaccharide's have different effects on the regulation of this potent stimulator of intake. It is also significant because it shows that fructose does not have the same ability to inhibit NPY-induced feeding as does glucose.

\section{Receptor Activity Modifying Protein 3}

Receptor activity modifying protein 3 (RAMP3) is a G protein-coupled receptor (GPCR) accessory protein in the family of RAMP. RAMP proteins were originally identified in association with calcitonin receptor-like receptors (CLR). One function of RAMP3 is to interact with the calcitonin receptor to produce amylin receptor complexes. Once formed, these complexes allow binding of amylin to the receptor. Another function of RAMP3 is to complex with calcitonin receptor-like receptor (CLR) to form adrenomedullin receptors $(15,58)$. Because the RAMP family plays such an important role in the transport and modulation of GPCRs, there have been extensive pharmacological studies aimed at examining RAMPs as potential sites 
for modulating GPCRs for the sake of disease treatment. Though much is known about the function of this protein, little has been reported on the specific impact of RAMP3 in the control of intake and energy balance.

To examine the life-long impact of RAMP3 deletions and the overlapping effects of RAMP proteins, Dackor and colleagues developed mouse strains with targeted RAMP deletions. Although mice with RAMP2 deletions had severely impaired fertility, RAMP3 deletions did not show any phenotypic differences from control until later in life. In late life, animals lacking the $R A M P 3$ gene had difficulty maintaining body weight however the researchers note that the mechanism behind this is not yet understood (59).

\section{Tumor Necrosis Factor}

Tumor Necrosis Factor- $\alpha$ (TNF- $\alpha)$ is a 212 amino acid inflammatory cytokine found in the hypothalamus. TNF plays in active role in inflammation and obesity and is involved in lipid metabolism regulation, adipocyte differentiation, and insulin sensitivity (60). TNF has been shown to interact with well-known satiety signals such as leptin. Huypens has proposed a model for TNF that suggests the gene has a role in the regulation of the inverse relationship between ADIPOQ and leptin (61).

In a study by Wang and colleagues rats were fed a high fat diet to induce obesity then were switched to a chow diet. Gene expression experiments revealed that many inflammatory cytokines, including TNF, were elevated following induction of obesity. After the switch to a regular chow diet however, the upregulation of these TNF did not return to normal. This suggests that it may not be possible to reduce the 
inflammatory response that results from obesity (62). This is an important finding that may impact the way obesity therapies are designed.

\section{Thyrotropin Releasing Hormone}

Thyrotropin- releasing hormone (TRH), also called Thyrotropin- releasing factor (TRF), is a 242 amino acid hormone produced in the PVN of the hypothalamus that functions to stimulate the release of thyroid stimulating hormone and prolactin from the anterior pituitary. TRH is an anorectic hormone.

The mechanism of TRH action on appetite regulation is not yet fully understood (63). Zhang and van den Pol found that in addition to reducing intake, body weight and sleep, central injections of TRH also inhibited melaninconcentrating hormone $(\mathrm{MCH})$ neurons. $\mathrm{MCH}$ neurons increase food intake (64). This finding may suggest that the reduction of food intake following TRH administration may be through TRH acting on MCH neurons (63).

Leptin has been found to have direct and indirect (through activating POMC neurons that in turn release $\alpha \mathrm{MSH}$ to stimulate TRH) effects on stimulation of TRH synthesis (65). NPY also acts on TRH as an inhibitor through activation of NPY receptors on the TRH neurons (66). 
Chapter 2: Effects of Sugar Solutions on Hypothalamic Appetite Regulation 


\section{Introduction}

Despite years of research, and millions of dollars spent every year in prevention and treatment, obesity has become the nation's most preventable health problem $(1,2)$. The current obesity epidemic is not attributable to any one factor, and is not restricted by race, nationality, age or gender (3). Despite its prevalence, there is no known cure for this disease. Several hypotheses about how obesity develops have been proposed that help guide research efforts.

One such hypothesis is that dietary patterns of Americans have significantly shifted over the past fifty years by including unprecedented amounts of refined sugar (4). Others have added that not all sugars are the same, and that fructose in particular accounts for much of the increase in sugar intake in the American diet $(5,6)$. From 1970 to 1990 , consumption of high fructose corn syrup (HFCS) increased more than $1000 \%$ and currently accounts for $40 \%$ of all added caloric sweeteners $(7,8)$.

Evidence that fructose is capable of promoting excessive weight gain has been reported in animal models and in humans. Figure 1 depicts the trends of overweight and obesity with the increase in fructose consumption in the US over the years. Rats maintained on a diet rich in HFCS for 6 or 7 months show abnormal weight gain, increased circulating TG and augmented fat deposition (9). This hypothesis is not without its critics. Several groups have reported that when tested side-by-side, fructose is no more or less effective in promoting excess weight gain $(10,11)$.

However, the rise in circulating TG can be explained by the metabolism of fructose. Fructose is metabolized differently than glucose, the more common monosaccharide. These metabolic pathways are outlined in Figure 2. To summarize, 
when glucose enters the cell there are multiple control points that regulate the conversion of glucose to fat (triglycerides). However these control points do not exist in the metabolism of fructose and thus fructose is readily metabolized into triglycerides.

In the laboratory, sugar-induced obesity can be studied by giving rats access to any of a wide variety of sugar solutions, from which they will consume approximately $60 \%$ of their total daily caloric intake from the solution, despite differences in concentration and sweetness (12-14). Long term access to sucrose, glucose, and fructose promote increased weight gain and a shift in body composition favoring increased fat deposition (9). Despite the extensive behavioral examinations of the rat's avidity for sugar solutions, relatively little work has been focused on the impact of sugar intake on the hepatic and central mechanisms controlling intake. Exceptions to this characterization are the work of Erlanson-Albertsson and colleagues, who have demonstrated that fructose can upregulate fatty acid amide hydrolase, an enzyme involved in the degradation of hypothalamic endocannabinoids, as well as other enzymes involved in the synthesis of endocannabinoids (67). Hoebel and colleagues have reported on the pronounced effects of sugar solutions on the release of dopamine in the nucleus accumbens (NAc), the brain's so-called "reward center" $(68,69)$. In addition to dopamine release, this group has demonstrated that sugar consumption can alter receptor gene expression in reward areas of the brain.

We have more recently added to this literature by reporting that fructose consumption can promote increased oxoreductase activity of 11 beta hydroxysteroid 
dehydrogenase -1 , an enzyme that regulates intracellular glucocorticoids in adipose tissue $(70,71)$.

The purpose of the present experiment was to directly compare the efficacy of fructose with high fructose corn syrup. To do this, we used a PCR array system which evaluates 86 different obesity related genes on hypothalamic tissue. Once genes with significant changes were identified, we verified the array findings using traditional RT-PCR using primers that were designed in house (pooled verification). To further verify these findings gene expression in individual animals was evaluated with these primers as well (individual verification). It was our intention to establish a sound collection of evidence from these three approaches to determine the effects of sugars on hypothalamic, appetite-regulatory, gene expression. 


\section{Materials and Methods}

\section{Animals}

Adult male Sprague-Dawley (CD strain) rats (Charles River Laboratories, Wilmington, MA) with a mean weight of approximately 300 grams were used. Upon arrival, all animals were individually housed and maintained on a $12 \mathrm{~h}$ light/dark cycle with a room temperature of $22^{\circ} \mathrm{C} \pm 1^{\circ} \mathrm{C}$. During the $1 \mathrm{wk}$ acclimation period the rats were given free access to the control diet and water. Animals were weighed and $24 \mathrm{~h}$ food intake and sugar solution intake (when appropriate) were measured daily at 0900h throughout the experiment.

All rats were killed by slow replacement of air in a specialized chamber with pure $\mathrm{CO}_{2}$ followed by rapid decapitation and exsanguination. This method has been approved for use by the Panel on Euthanasia of the American Veterinary Medical Association as well as the UM IACUC. All procedures described herein are in compliance with the University of Maryland's IACUC guidelines.

\section{Animal Diets}

The control diet used in these experiments is based upon one previously used in an experiment that manipulated quality and quantity of fat in diet-induced obesity studies with rats (72). The diet is a nutritionally complete low fat diet [Rodent diet 7012] prepared by Harlan Teklad (Bethlehem, PA) and provides 3.41 metabolizable $\mathrm{kcal} / \mathrm{g}$ of diet. Per gram of chow, $2.14 \mathrm{kcal}$ were derived from carbohydrate, $0.79 \mathrm{kcal}$ was derived from protein, and $0.51 \mathrm{kcal}$ was derived from fat. All animals were given free access to water throughout the experiment. 


\section{Study Design}

Rats $(\mathrm{N}=44)$ were randomly assigned to one of five weight-matched groups $(\mathrm{n}=8$, control $\mathrm{n}=12)$ after an initial $1 \mathrm{wk}$ acclimation period during which they had ad lib access to food and water. The rats assigned to the first group had ad libitum control diet (Harlan rodent diet 7012) only, and served as the control group. Rats assigned to the second group had ad libitum access to the control diet and free access to a $16 \%$ weight/volume fructose (Tate \& Lyle, Decatur IL) solution. Rats assigned to the third group had ad libitum access to the control diet plus free access to a $16 \%$ glucose weight/volume (Sigma Aldrich, St Louis MO) solution. Rats assigned to the fourth group had ad libitum access to the control diet and free access to $16 \%$ high fructose corn syrup (HFCS) weight/volume (Tate \& Lyle, Decatur IL), Finally, rats assigned to the fifth group had ad libitum access to the control diet and free access to a $16 \%$ weight/volume sucrose (Domino Foods, Baltimore MD) solution. All sugar solutions were prepared $24 \mathrm{~h}$ in advance and stored at $4^{\circ} \mathrm{C}$. The rats were maintained on their respective diets for $24 \mathrm{~h}$ and then sacrificed. At the time of sacrifice, livers (lobus lateralis sinister) were dissected and flash frozen for storage at $-80^{\circ} \mathrm{C}$. Brains were removed and flash frozen at $-80^{\circ} \mathrm{C}$ for subsequent dissection. Frozen brains were sectioned using an IEC Minot Custom Microtome (Damon/IEC Division) and 89, 80-100 micron-thick consecutive tissue slices were sectioned from the hypothalamic region starting at the interaural line $+6.44 \mathrm{~mm}$. Figure 3 shows the hypothalamic region of interest. 


\section{Plasma Measures}

Plasma insulin concentrations were measured by ELISA (LINCOplex; LINCO Research). Plasma glucose concentrations were measured enzymatically (Smith-Kline Beecham Laboratories). All reactions were run in duplicate.

The Dimension clinical chemistry system Flex reagent cartridge (Siemens Healthcare Diagnostics, Newark, DE) was used with a Dade Behring Dimension Xpand automated system to quantify plasma triglyceride levels. The assay is based on an enzymatic procedure using a combination of lipoprotein lipase, glycerol kinase, glycerol-3-phosphate-oxidase, and peroxidase. Changes in absorbance $(510,700 \mathrm{~nm})$ resulting from the formation of quinoneimine from hydrogen peroxide reflect the total amount of glycerol and its precursors. All reactions were run in duplicate.

\section{RNA Extraction}

Total RNA was extracted from each hypothalamic sample according to RNeasy Mini and RNeasy Lipid (QIAGEN) kit directions. The samples were purified with DNA-free (Ambion) and analyzed spectrophotometrically (Nanodrop) to determine concentration and check for quality. cDNA template was created for each sample from 500ng of purified RNA using SuperScript III Reverse Transcriptase (Invitrogen).

\section{cDNA Synthesis}

cDNA was made using the SABiosciences RT² First Strand Kit. A genomic DNA elimination mixture was first created using 15 ug RNA samples from each 
group (equal quantity from each animal) that was then mixed with $2.0 \mathrm{ul}$ of $5 \mathrm{X}$ qDNA elimination buffer and RNase-free $\mathrm{H}_{2} \mathrm{O}$ to a final volume of $10 \mathrm{ul}$. Contents were mixed gently, incubated at $42^{\circ} \mathrm{C}$ for 5 minutes and chilled on ice. An RT cocktail was then prepared, containing 5X RT Buffer 3, Primer \& External Control Mix, RT Enzyme Mix 3, and RNase free $\mathrm{H}_{2} 0.10 \mathrm{ul}$ of the RT cocktail was added to each genomic DNA elimination mixture, mixed well, and incubated at $42^{\circ} \mathrm{C}$ for exactly 15 min and then immediately stopped by heating at $95^{\circ} \mathrm{C}$ for $5 \mathrm{~min} .91 \mathrm{ul} \mathrm{of} \mathrm{ddH}_{2} \mathrm{O}$ was added to each $20 \mathrm{uL}$ of cDNA synthesis reaction and the solution was mixed well and stored at $-20^{\circ} \mathrm{C} .34 \mathrm{uL}$ of each sample from each experimental group was taken and pooled to create the master stock of cDNA used for the arrays and pooled verification assay. Hypothalamic cDNA templates from each experimental group were pooled by diet.

\section{Measurement of Gene Expression}

Changes in gene expression were measured in three ways, $\mathrm{RT}^{2} \mathrm{PCR}$ array, pooled verification, and an individual verification. Hypothalamic cDNA from each group was pooled and served as the genetic material for both the array and the pooled verification assay. After completing the array, 'significant' results were identified and those that were 'significant' and also of interest to the study of sugars effects on hypothalamic appetite regulation were selected for follow up verification assays. Primers were designed for each of these genes and standard RT-PCR experiments were run using pooled hypothalamic cDNA (pooled verification). If quality results were obtained from the pooled verification, the individual verification assay was run. 
In the individual verification assay, hypothalamic cDNA from individual rats $(n=4$ per group) were analyzed using aforementioned primers and standard RT-PCR, results were then averaged for each group. Selection of the four animals included in the individual verification was based on those with the highest quality cDNA as analyzed spectrophotometrically (Nanodrop).

\section{$R^{2}$ Profiler $^{\mathrm{TM}}$ PCR Array}

Ten Rat Obesity RT² Profiler ${ }^{\mathrm{TM}}$ PCR Arrays (PARN-017A) were purchased from SABiosciences (Frederick, MD). Each array profiled the expression of 84 genes related to obesity, including genes that code for orexigenic peptides, hormones, and receptors, anorectic peptides, hormones, and receptors, and central and peripheral signaling molecules related to energy expenditure. Arrays also include 5 housekeepers and 7 controls. See appendix A for the complete list of genes included in the array.

Diluted First Strand cDNA was added to the $2 \mathrm{X}$ SABiosciences RT ${ }^{2}$ qPCR Master Mix and aliquoted into each of 96-wells of the obesity arrays. Arrays were run according to the SABiosciences protocol: $95^{\circ} \mathrm{C}$ for $10 \mathrm{~min}$, and 40 cycles at $95^{\circ} \mathrm{C}, 15$ $\mathrm{s}$; and $60^{\circ} \mathrm{C}, 1 \mathrm{~min}$. Results were analyzed using the SABioscience's online $\mathrm{RT}^{2}$ Profiler ${ }^{\mathrm{TM}}$ PCR Array Data Analysis software. Fold change was calculated as $2^{\wedge}(-$ $\mathrm{ddCt}$ ) using SABioscience's online PCR array analysis software. Fold change of 0.5 or less or of 1.5 or greater were considered 'significant.' 


\section{Custom Primer Design and Optimization}

Using the array data as a guide, primers were designed for the majority of the genes that were significantly upregulated or downregulated in the array to be used in conventional RT PCR reactions. These included: ADIPOQ, ADRA2b, AGRP, APOA4, CCK, CLPS, CRH, DRD1a, GH1, IAPP, NPY, RAMP3, TNF, TRH, and UCN. Additionally, $\beta$ actin, Ribosomal protein, large, P1 (RPLP1), Glyceraldehyde 3-phosphate dehydrogenase (GAPDH), and Lactate dehydrogenase A (LDHA) were evaluated as housekeepers. Upon initial evaluation, LDHA was eliminated as an option for housekeeper because the average $\mathrm{Ct}$ was much higher than with the other housekeeper options. With the exception of TNF, primers were designed using Beacon Designer 7 software default parameters (PREMIER Biosoft, Palo Alto, CA). TNF was sourced from Yang et al, 2011(73).

Primers were evaluated using the CFX96 (BioRad) protocol, using a gradient that was centered around predicted optimum annealing temperature (TaOpt). The protocol for primer verification PCR is as follows: $95^{\circ} \mathrm{C}, 3 \mathrm{~min}$, and 40 cycles at $95^{\circ} \mathrm{C}$ for $10 \mathrm{sec}$, at a gradient of temperatures for $30 \mathrm{sec}$ with subsequent melt curve of $65^{\circ}-95^{\circ} \mathrm{C}$ at increments of $0.5^{\circ} \mathrm{C}$ for $5 \mathrm{sec}$. Empirically optimal Ta was determined for each primer set from these results. Housekeepers were selected based on the least variation in cycles between groups. See Table 1 for primer sequences and optimal annealing temperatures. 


\section{Pooled Verification Assay}

Following determination of $\mathrm{TaOpt}$ from the primer verification assay, successful primers were evaluated on pooled group cDNA (glucose, sucrose, HFCS, fructose, and control). RPLP1 served as the housekeeper for each gene of interest. All reactions were carried out in duplicate.

Fold change was calculated as $2^{\wedge}(-\mathrm{ddCt})$. Fold change of 0.5 or less or of 1.5 or greater were considered 'significant.'

\section{Individual Verification Assay}

cDNA was synthesized from individual animals with highest quality RNA, four animals per group, as previously described. Primers that were successful on the group level were evaluated on 20 individual rat cDNA (4 animals from each group). RPLP1 served as the housekeeper for each gene of interest. All reactions were carried out in duplicate.

Fold change was calculated as $2^{\wedge}(-\mathrm{ddCt})$. Fold change of 0.5 or less or of 1.5 or greater were considered 'significant.' 


\section{Findings}

\section{Body Weight}

Twenty-four hour access to any of the four sugar solutions used failed to promote significant differences in body weight $(\mathrm{p}<0.05)$. Refer to body weight data presented in Table 2.

\section{Intake}

\section{Chow}

All four treatment groups consumed significantly less chow $(\mathrm{p}<0.001)$ than did controls during the $24 \mathrm{~h}$ access period. HFCS fed animals consumed significantly less chow than either fructose or glucose fed groups $(\mathrm{p}<0.05)$ Refer to intake data presented in Table 3.

\section{Sugar}

HFCS fed animals consumed significantly greater amounts of sugar compared to the group fed glucose $(\mathrm{p}<0.05)$. No other differences among groups were found. Refer to intake data presented in Table 3.

\section{Total Intake}

Control animals consumed significantly fewer total calories than the groups given access to sugar solutions $(\mathrm{p}<0.05)$. No other differences were observed. Refer to intake data presented in Table 3. 


\section{Plasma Analyses}

Fructose consumption caused significant upregulation in circulating triglycerides $(\mathrm{p}<0.05)$. No differences among the five groups in plasma insulin or plasma glucose were found. Refer to plasma data presented in Table 4 .

\section{Housekeeper Selection}

It has long been recognized that the selection of a housekeeper gene should be determined by that gene's resistance to treatment effects. We examined several standard housekeepers and found that all but one was significantly affected by sugar solution consumption. RPLP1 was the only primer analyzed whose cycle threshold did not vary across treatments (Duncan's new multiple range test $\mathrm{p}<0.05$ ). Refer to housekeeper selection data presented in Table 5.

For these reasons, $\beta$-Actin, and GAPDH were excluded as options for housekeeper, leaving RPLP1 to be used as reference gene for all subsequent analyses.

\section{Gene Expression}

\section{Inclusion and Exclusion Criteria}

In order to expedite the interpretation of the many possible outcomes of the array analysis, we sorted the data into two categories: 'significant' and 'not significant' Fold change of 0.5 or less or of 1.5 or greater were considered 'significant.' Fold change was calculated as $2^{\wedge}(-\mathrm{ddCt})$ using SABiosciences online PCR array analysis software. Comparisons were based on average of duplicate 
assays. Refer to Appendix B for complete results of PCR array analyses. Refer to Table 6 for a list of those genes that were 'significant.'

Additionally, data were not included for subsequent analyses if mean thresholds were higher than 36 cycles, suggesting that the existing message concentrations in these samples were too low for consideration. Subsequent individual verification PCR was not performed

\section{Adiponectin (ADIPOQ)}

ANOVA performed on PCR array analyses did not reveal any significant differences among treatments (ANOVA F=4.23, $\mathrm{df}=4, \mathrm{P}=0.0729$ ). Duncan's new multiple range test however revealed a significant upregulation of ADIPOQ message with glucose consumption (374\%). In glucose fed animals ADIPOQ was significantly upregulated when compared to control as was sucrose and HFCS. Though upregulated $236 \%$, the fructose group did not differ from the other experimental groups $(\mathrm{p}<0.05)$. Data are presented in Table 7.

ANOVA was not applied to the pooled PCR data due to fact that the mean thresholds were higher than 36 cycles, suggesting that the existing message concentrations in these samples was too low for consideration. Because of this, subsequent individual verification PCR was not performed.

\section{Adrenergic 2b receptor (ADRA2b)}

Analysis of variance applied to the PCR array data revealed that access to a sugar solution significantly affected ADRA2b message (ANOVA $F=20.09, \mathrm{df}=4$, 
$\mathrm{p}=0.003$ ). Post hoc analyses of group means found that ADRA2b in the hypothalamus was significantly downregulated by fructose by $52 \%$ and HFCS by $65 \%$ (Duncan's new multiple range test, $\mathrm{p}<0.05)$. The mean fold change of the glucose group was significantly higher than that of the sucrose group, but neither differed from control. Data are presented in Table 8.

ANOVA applied to the verification assay replicated the observation that sugar access significantly affected ADRA2b message (ANOVA $\mathrm{F}=163.38, \mathrm{df}=4$, $\mathrm{p}<0.0001)$. Duncan's new multiple range tests revealed that glucose and sucrose significantly upregulated ADRA2b message by $1461 \%$ and $1180 \%$ respectively $(\mathrm{p}<0.05)$. The two groups were significantly different from each other and both were different from the remaining experimental groups. No other statistically significant differences were observed. Data are presented in Table 8.

ANOVA was not applied to the individual PCR data due to fact that the mean thresholds were higher than 36 cycles, suggesting that the existing message concentrations in these samples was too low for consideration.

\section{Agouti related peptide (Agrp)}

ANOVA applied to the array data revealed that sugar access had a significant effect on AGRP message in the hypothalamus (ANOVA $\mathrm{F}=18.73, \mathrm{df}=4, \mathrm{p}=0.0033$ ). HFCS promoted a 199\% upregulation of AGRP message when compared to control $(\mathrm{p}<0.05)$. No other differences were observed. Data are presented in Table 9. ANOVA applied to the pooled data failed to reveal any effect of sugar access to hypothalamic AGRP message (ANOVA $\mathrm{F}=1.36, \mathrm{df}=4, \mathrm{p}=0.3661$ ). Results from 
Duncan's new multiple range test verified that there were no differences between group $(\mathrm{p}>0.05)$. Data are presented in Table 9.

Similarly, ANOVA of individual verification assays revealed no significant effect of sugar access on AGRP message (ANOVA F=1, df=3, p=0.4659). Duncan's new multiple range test revealed that there was a $3222 \%$ upregulation in AGRP message with consumption of HFCS $(\mathrm{p}<0.05)$. Data are presented in Table 9.

\section{Apolipoprotein A-IV (APOA4)}

ANOVA applied to the PCR array data revealed that there are differences in APOA4 expression with consumption of different sugars (ANOVA $F=18.8, \mathrm{df}=4$, $\mathrm{P}=0.0032$ ). Duncan's new multiple range test revealed that the only significant changes were the downregulation of APOA4 message $(\mathrm{p}<0.05)$. The greatest change was a downregulation of $70 \%$ that resulted from sucrose intake. Also significant was a 39\% downregulation of APOA4 by fructose consumption. Data are presented in Table 10.

ANOVA was not applied to the pooled PCR data due to fact that the mean thresholds were higher than 36 cycles, suggesting that the existing message concentrations in these samples was too low for consideration. Because of this, subsequent individual verification PCR was not performed.

\section{Cholecystokinin (CCK)}

Variations in sugar solutions have significant effects on the regulation of CCK in the hypothalamus, as revealed by a significant group effect (ANOVA F=566.95, 
$\mathrm{df}=4, \mathrm{p}<0.0001)$. The PCR array revealed that glucose promoted a $198 \%$ upregulation of CCK in the hypothalamus. HFCS and sucrose upregulated CCK expression by $139 \%$ and $123 \%$ respectively. By contrast, fructose promoted a $37 \%$ reduction in CCK expression as compared to control. Duncan's new multiple range tests that were used to determine differences between group mean fold changes revealed that all groups were statistically different from one another and control $(\mathrm{p}<0.05)$. Data are presented in Table 11.

For the most part, results from the PCR array were replicated in the pooled verification analyses. Glucose was markedly upregulated, 187\%, and fructose was markedly downregulated, $60 \%$ in the pooled analyses. The Duncan's new multiple range test revealed that these differences were statistically different from each other $(\mathrm{p}<0.05)$ as well as the remaining experimental groups. No differences were observed between the control group and the sucrose and HFCS groups. Data are presented in Table 11.

Due to variability between animals, results from the individual verification analyses were not significant using ANOVA ( $\mathrm{F}=164.45, \mathrm{df}=4, \mathrm{p}=0.0984)$. However, subsequent Duncan's new multiple range test confirmed the observation for the pooled verification that glucose caused the greatest upregulation (637\%) in CCK message $(\mathrm{p}<0.05)$. Data are presented in Table 11.

\section{Colipase (CLPS)}

ANOVA applied to the PCR array data revealed that there are no differences in CLPS expression with consumption of different sugars (ANOVA F $=0.56, \mathrm{df}=4$, 
$\mathrm{P}=0.7)$. Duncan's new multiple range tests further revealed that there were not significant changes in CLPS. Data are presented in Table 12.

ANOVA was not applied to the pooled PCR data due to fact that the mean thresholds were higher than 36 cycles, suggesting that the existing message concentrations in these samples was too low for consideration. Because of this, subsequent individual verification PCR was not performed.

\section{Corticotropin Releasing Hormone (CRH)}

Results from ANOVA of PCR array data revealed that different sugars result in significant changes in the expression of CRH in the hypothalamus (ANOVA $\mathrm{F}=20.09, \mathrm{df}=4, \mathrm{p}=0.0028)$. Subsequent post hoc tests revealed HFCS induced a 51\% downregulation in $\mathrm{CRH}$ expression $(\mathrm{p}<0.05)$. The remaining groups did not differ from control. Data are presented in Table 13.

Results from the array were replicated in the pooled verification. Sugar consumption caused significant changes in $\mathrm{CRH}$ expression (ANOVA F=163.38, $\mathrm{df}=4, \mathrm{p}<0.0001$ ). Fructose was upregulated by $124 \%$ (Duncan's new multiple range test $\mathrm{p}<0.05)$. Also, both glucose and HFCS ingestion resulted in downregulation of CRH message in the hypothalamus, by $28 \%$ and $73 \%$ respectively. Sucrose did not significantly affect expression. The remaining groups significantly differed from control. Data are presented in Table 13.

In both the array and the pooled verification, HFCS caused a significant downregulation in CRH expression. Data are presented in Table 13. 
Because of time and resource limitations individual verification was not performed for CRH.

\section{Dopamine Receptor 1a (DRD1a)}

Results from ANOVA revealed a significant effect of sugar consumption on expression in DRD1a using the PCR array system (ANOVA F=52.33, df=4, $\mathrm{p}=0.0003$ ). Duncan's new multiple range test determined that both HFCS and sucrose caused changes in DRD1 a expression that was significantly different from control ( $p<0.05)$. HFCS was upregulated $207 \%$ and sucrose was downregulated $30 \%$. Remaining groups did not differ from control. Data are presented in Table 14.

The subsequent pooled verification assay also revealed differences between experimental groups (ANOVA F=5.38, $\mathrm{df}=4, \mathrm{p}=0.0467$ ). Duncan's new multiple range test found that glucose and HFCS did not differ from control $(\mathrm{p}<0.05)$. Fructose caused a $415 \%$ upregulation of DRD1a message $(\mathrm{p}<0.05)$. Sucrose also caused a significant upregulation in DRD1a expression, 332\% ( $\mathrm{p}<0.05)$. Data are presented in Table 14.

ANOVA was not applied to the individual PCR data due to fact that the mean thresholds were higher than 36 cycles, suggesting that the existing message concentrations in these samples was too low for consideration. Data are presented in Table 14. 


\section{Growth hormone (GH1)}

Different sugar solutions caused significant changes in expression of GH1 as revealed by a group effect (ANOVA F=12.96, $\mathrm{df}=4, \mathrm{p}=0.0075)$. Using the PCR array system we found that glucose causes a $332 \%$ upregulation in expression of the GH1 gene when compared to controls (Duncan's new multiple range test $\mathrm{p}<0.05$ ). No other significant differences were observed between groups. Data are presented in Table 15.

The pooled verification analysis also revealed a significant group effect of sugar solutions on $\mathrm{GH} 1$ expression (ANOVA F=31.7, $\mathrm{df}=4, \mathrm{p}=0.001$ ). Using Duncan's new multiple range test, it was again observed that glucose consumption results in a significant upregulation of GH1, 393\% ( $<<0.05)$. Fructose fed animals also expressed upregulation of hypothalamic GH1 by $254 \%$. Upregulation was also observed, though less robust, in the sucrose group with a $167 \%$ increase in the expression of GH1. Data are presented in Table 15.

ANOVA was not applied to the individual PCR data due to fact that the mean thresholds were higher than 36 cycles, suggesting that the existing message concentrations in these samples was too low for consideration. Data are presented in Table 15.

\section{Islet amyloid polypeptide (IAPP)}

Although results from the PCR array do not reveal any differences between treatments for IAPP expression (ANOVA F=1.4, $\mathrm{df}=4, \mathrm{p}=0.3552$ ), ANOVA of pooled verification $\operatorname{did}(\mathrm{ANOVA} F=55.13, \mathrm{df}=4, \mathrm{p}=0.0003)$. In the pooled 
verification, there was a $483 \%$ upregulation of hypothalamic IAPP message induced by glucose consumption (Duncan's new multiple range test $\mathrm{p}<0.05$ ). Fructose also induced upregulation of IAPP message with a mean fold change of 2.98. No other significant changes were observed. Data are presented in Table 16.

ANOVA was not applied to the pooled verification PCR data due to fact that the mean thresholds were higher than 36 cycles, suggesting that the existing message concentrations in these samples was too low for consideration. Data are presented in Table 16.

\section{Neuropeptide Y (NPY)}

Results from the PCR array revealed that HFCS had a significant impact on NPY expression (ANOVA F=24.08, $\mathrm{df}=4, \mathrm{p}=0.0018$ ). Duncan's New Multiple range tests that were used to determine differences between group means revealed that HFCS promoted a $227 \%$ upregulation in the expression of NPY in the hypothalamus when compared to controls $(\mathrm{p}<0.05)$. No other significant differences between group means were observed. Data are presented in Table 17.

ANOVA applied to the subsequent pooled verification analyses revealed a significant treatment effect (ANOVA F=36.07, $\mathrm{df}=4, \mathrm{P}=0.0007$ ). The Duncan's new multiple range tests failed to replicate the upregulation of NPY observed with the array analyses. No statistically significant difference between the HFCS fed animals and controls was found. On the other hand, glucose fed animals had a $49 \%$ reduction in NPY expression as compared to control $(\mathrm{p}<0.05)$. Data are presented in Table 17. 
Individual verification analyses replicated the array results (ANOVA F=16.33,

$\mathrm{df}=4, \mathrm{p}<0.001)$. Hypothalamic NPY in HFCS fed rats was upregulated by $352 \%$ compared to control. The downregulation of NPY message in glucose fed animals, as observed in the pooled verification analysis, failed to replicate. Data are presented in Table 17.

In both the pooled verification as well as the individual verification, no differences were observed between sucrose and fructose fed animals. Both groups showed slight downregulation in the pooled verification (approximately 25\% less then control, and in individual verification assay results showed approximately a $25 \%$ upregulation as compared to control.

\section{Receptor (G protein-coupled) activity modifying protein 3 (RAMP3)}

Results from the PCR array analysis revealed that sugars caused significant changes in the expression of RAMP3 (ANOVA F=36.03, $\mathrm{df}=4, \mathrm{P}=0.0007$ ). Results from Duncan's new multiple range tests revealed specific differences in RAMP3 regulation by different sugar solutions. Glucose resulted in the greatest upregulation, (by $132 \%$ as compared to control, $\mathrm{p}<0.05$ ). Fructose and HFCS however promoted downregulation in hypothalamic RAMP3 expression, by $47 \%$ and $56 \%$ respectively (both $\mathrm{p}<0.05$ ). RAMP3 expression in animals consuming sucrose did not differ from control $(\mathrm{p}>0.05)$. Data are presented in Table 18 .

Results from the pooled verification analysis replicated the results from the PCR array. ANOVA revealed that there were significant differences between the treatment groups and the control (ANOVA F=304.63, $\mathrm{df}=4, \mathrm{P}<0.0001$ ). As was in 
the PCR array results, glucose promoted the greatest upregulation of RAMP3 expression, by $170 \%(\mathrm{p}<0.05)$. HFCS and fructose downregulated RAMP3 message by $45 \%$ and $43 \%$ respectively (both $\mathrm{p}<0.05$ ). Sucrose led to an upregulation of RAMP3 expression. RAMP3 in the sucrose group was significantly higher than the other treatment groups as well as the control, 147\% (Duncan's new multiple range test $\mathrm{p}<0.05)$. Data are presented in Table 18 .

Differences in treatment groups were not significant in the individual verification experiment (ANOVA F=19.63, df=4, P=0.4603). However, Duncan's new multiple range test revealed animals fed HFCS had a $243 \%$ upregulation in RAMP3 expression. Sucrose and control did not differ. Glucose and fructose fed animals both showed significant downregulation by $35 \%$ and $93 \%$ respectively. Differences between glucose and fructose were significant $(\mathrm{p}<0.05)$. Data are presented in Table 18.

\section{Tumor Necrosis Factor (TNF- $\alpha)$}

Results from the PCR array did not reveal any significant differences in TNF$\alpha$ expression when analyzed with ANOVA $(\mathrm{F}=3.87, \mathrm{df}=4, \mathrm{P}=0.085)$. Duncan's new multiple range test however did reveal significant differences between glucose and HFCS and control $(\mathrm{p}<0.05)$. Glucose, upregulated TNF- $\alpha$ by $165 \%$, differed from HFCS and control. Sucrose and fructose did not differ from any other experimental groups. Data are presented in Table 19.

Results from the pooled verification were significant when analyzed with ANOVA ( $\mathrm{F}=15.96, \mathrm{df}=4, \mathrm{P}=0.0047)$. Glucose, sucrose and fructose significantly 
upregulated hypothalamic TNF- $\alpha$ as compared to control though they were not significantly different amongst themselves (glucose 148\%, sucrose 167\% and fructose 167\%) (Duncan's new multiple range test $p<0.05$ ). TNF- $\alpha$ expression in rats fed HFCS however did not differ from control $(\mathrm{p}>0.05)$. Data are presented in Table 19. ANOVA was not applied to the individual verification PCR data due to fact that the mean thresholds were higher than 36 cycles, suggesting that the existing message concentrations in these samples was too low for consideration. Data are presented in Table 19.

\section{Thyrotropin Releasing Hormone (TRH)}

ANOVA applied to the PCR array data revealed significant differences in TRH expression in experimental groups (ANOVA F=32.89, $\mathrm{df}=4, \mathrm{P}=0.0009$ ). Subsequent post-hoc analyses (Duncan's new multiple range test) further revealed the greatest change in TRH expression was from consumption of HFCS that promoted a $57 \%$ downregulation as compared to control $(\mathrm{p}<0.05)$. Glucose and sucrose also downregulated TRH by $45 \%$ and $23 \%$ respectively. By contrast, fructose consumption promoted an upregulation of $122 \%(\mathrm{p}<0.05)$. Data are presented in Table 20.

Pooled verification ANOVA analysis also revealed differences in experimental groups (ANOVA $\mathrm{F}=37.56, \mathrm{df}=4, \mathrm{P}=0.0006$ ). All treatment groups with the exception of HFCS were upregulated when compared to control. The greatest upregulation in TRH expression was that in animals given access to sucrose solutions by $504 \%$. This is in conflict to the results observed from the PCR array in which 
sucrose fed rats had a $23 \%$ downregulation in TRH expression. Glucose and fructose also significantly upregulated TRH message by $386 \%$ and $372 \%$ respectively. Lastly, HFCS consumption resulted in the least change in message of $122 \%(\mathrm{p}<0.05)$. Data are presented in Table 20.

Because of time and resource limitations individual verification was not performed for TRH.

\section{Urocortin (UCN)}

Results from the ANOVA of PCR array data revealed that there were significant differences in treatment groups (ANOVA F=116.76, $\mathrm{df}=4, \mathrm{P}<0.0001$ ). Further post-hoc analyses revealed that the only significant difference was an 111\% upregulation of hypothalamic UCN by glucose consumption ( $\mathrm{p}<0.05)$. The remaining groups did not differ from control. Data are presented in Table 21.

ANOVA was not applied to the pooled or individual PCR data due to fact that the mean thresholds were higher than 36 cycles, suggesting that the existing message concentrations in these samples were too low for consideration. Data are presented in Table 21. 


\section{Discussion}

It is well accepted that there is an alarming obesity epidemic in this country. The obesity problem is particularly worrying not only in terms of human health and quality of life but also in terms of dollars spent on healthcare in the treatment of obesity related comorbidities. Obesity has become the nation's most preventable health problem $(1,2)$. Despite it's prevalence, there is no known cure for this disease or consensus about how it develops. One hypothesis for the cause of obesity is that dietary intake patterns of Americans have significantly shifted over the past fifty years by including unprecedented amounts of refined sugar (4).

The purpose of this experiment was to examine this hypothesis by evaluating how sugars affect the appetite regulatory center of the brain, the hypothalamus. Animals were given 24 hour access to either a dilute glucose, sucrose, HFCS, or fructose sugar solution. Intake of both chow and sugar was measured. Hypothalamic tissue was collected and changes in gene expression were measured using a RT-PCR array as well as traditional RT-PCR on pooled tissue samples (pooled verification) and individual rat samples (individual verification).

\section{Intake}

Previous studies have shown that initial presentation of a sugar solution will result in rats consuming excess calories from sugar. Over time however this result washes out and total caloric intake returns to a level that resembles control $(70,74)$. These findings may suggest an explanation for our results that sugar fed animals all consumed increased calories as compared to control animals. All sugar-fed animals 
consumed the same amount of total calories and there were no differences in percent kcal from sugar for groups consuming fructose containing sugars (sucrose, HFCS, fructose).

The rats in this experiment did not increase intake of glucose-fructose disaccharides (sucrose and HFCS) in such a way as to match the amount of fructose consumed in the fructose group. In other words rats did not have a threshold for fructose consumption and compensate by consuming $50 \%$ more sucrose or $45 \%$ more HFCS to match the total consumption of fructose in the fructose fed group. We applied the same model as Collier and Bolles did in their 1968 sugar dilution studies. Looking at intake of various sugar dilutions in rats, Collier and Bolles found that regardless of the type of sugar presented, rats will increase their intake of a dilute sugar so as to take in a certain threshold amount of total grams of sugar (75). In the current study, this model was applied to dilutions of fructose intake. For example, sucrose fed animals had a solution that was $50 \%$ less fructose than the fructose animals. Replicating Collier and Bolles' findings, there was not set level for fructose intake as animals consuming sucrose and HFCS, which have less fructose, consumed the same amount of total kcal from sugar. These findings also show that fructose having a sweeter taste than glucose did not impact intake.

\section{Plasma}

Fructose caused a significant and robust increase in triglycerides with only 24 hours of access. This phenomenon has been previously reported in longer term 
fructose feeding studies in rats and in humans $(76,77)$. The importance of this finding is that hypertriglyceridemia occurred with only 24 hour access to fructose.

No differences in plasma insulin or glucose were observed, as all blood samples were collected under ad libitum feeding conditions.

\section{Gene expression}

By using the PCR array technique we were able to evaluate the effects of different sugars on multiple hypothalamic genes with a very fast turn over. As seen in Table 6, significant changes for glucose fed animals were only upregulations.

We had also expected to see sucrose and HFCS fed animals to have similar results. Surprisingly, there were no genes with significant changes observed in both groups. Given that HFCS and sucrose only slightly vary in composition, it is unclear why results from intake of these sugars were not similar. The lack of a similar effect or a dose dependent effect demonstrates a limitation of the present analysis. In the future, this problem may be resolved with increasing the number of animals in each group and also running more replicates of the array assay.

We selected genes for subsequent analyses (pooled and individual verifications) based on those with significant up or downregulation (1.5 fold change and above, or 0.5 fold change and below). From this list of significant genes we were able to select genes that had a known role in the regulation of $\mathrm{CHO}$ intake and metabolism or those with very robust changes to further explore and verify. 


\section{Cholecystokinin}

Cholecystokinin (CCK) is an anorexogenic peptide that is expressed in both the small intestine and the brain. Expression of CCK results in short duration reduction of meal size (23). CCK is also important in the regulation of insulin.

As shown here, glucose consumption results in significant upregulation of CCK. This has been observed in previous work in animals maintained on a high fat diet (27). The impact of glucose on CCK expression may be as a result of the interaction of CCK with insulin. Lo (2011) using CCK-KO mice, found that these animals had reduced insulin response. CCK is required for regulating both insulin secretion and glucose tolerance in mice on a high fat diet. Considering these findings, it is proposed that CCK is upregualated by glucose such that CCK can in turn stimulate insulin release.

Alternatively, fructose consumption resulted in significant downregulation of CCK (if you exclude information from the individual analysis). This is a novel finding and has yet to be discussed in the literature. It is known that fructose and glucose are metabolized differently (Figure 2). Because CCK is anorectic and is upregulated by glucose but down regulated by fructose it illustrates how the differences the two sugars interact metabolically. It is also interesting to note that $\mathrm{CCK}$ is an anorectic peptide and fructose fails to upregulate it. This point suggests that fructose may fail to induce satiation and thus allow for overeating. 


\section{Corticotrophin Releasing Hormone}

Corticotropin-releasing hormone $(\mathrm{CRH})$, also known as Corticotropinreleasing factor $(\mathrm{CRF})$ is an anorectic peptide secreted by neurosecretory cells of the parvocellular region of the periventricular nucleus (PVN) of the hypothalamus and carried via the portal system to the anterior lobe of the pituitary where it promotes ACTH production (30).

Ulrich-Lai and colleagues evaluated the effect of sucrose on CRF expression. They found that daily limited access to a sucrose sweetened drink resulted in decreased CRH mRNA expression (33). In the present study however, sucrose did not differ from control in either the PCR array or the pooled verification. On the other hand, HFCS (the other disaccharide in this study) intake did significantly downregulate CRH message. Though the aforementioned study did not measure changes to CRH with HFCS consumption, it is unclear why in this study HFCS replicates the finding while sucrose does not.

The literature also shows that when glucose decreases, CRH expression increases $(21,31,32)$. However in the present study the effects of increased glucose rather than reduced glucose were measured. Although no changes in CRH expression in glucose fed animals were observed, in the future this could be examined by comparing animals that had been fasted and then given a dose of glucose, to animals that had only been fasted. Utilizing different doses of glucose would allow the examination of the amount of glucose required to reduce $\mathrm{CRH}$ expression back to normal levels. 
Also, fructose, though not different from control, prevented the downregulation observed with HFCS. This is an interesting finding because it suggests a role of insulin in $\mathrm{CRH}$ expression. It should be mentioned that fructose does not initiate an insulin response, but HFCS does.

In the future it will be interesting to evaluate changes in CRH expression in animals consuming fructose that have been administered insulin. This experiment will provide interesting insight into connections between $\mathrm{CRH}$ and sugars as they relate to insulin.

\section{Growth Hormone}

GH is thought to be an anorexogenic peptide that not only contributes to the regulation of energy expenditure but also growth. However, there is limited literature surrounding the effects of Growth Hormone $(\mathrm{GH})$ on the regulation of energy balance and intake.

Growth hormone is another anorectic protein whose expression was upregulated by glucose intake. As was discussed in the intake sections, giving rats access to sugar solutions and chow results in increased total caloric intake, and at the same time a significant reduction in daily chow intake. Given the upregulation of GH it could be suggested that GH is playing a role in suppressing chow intake but not sugar intake. Sugar solution intake might be spared the suppression as the result of increased dopamine activation of the reward pathway.

We did not find any significant effects of fructose on GH and thus our results did not replicate the findings of Strauch that fructose stimulates GH secretion (51). 
One possible explanation may be that in the Strauch study, fructose was administered IV.

There has been interesting work done on the effects of fasting and obesity states on GH secretion (50). In the future it would be interesting to further explore the effects of both glucose and fructose on obese animals given only 24 hour access to these sugars. It could be predicted that glucose would be less able to increase GH expression due to changes in metabolic flexibility resulting from obesity.

\section{Receptor Activity Modifying Protein 3}

Receptor activity modifying protein 3 (RAMP3) is a G protein-coupled receptor (GPCR) accessory protein in the family of RAMP. One function of RAMP3 is to interact with the calcitonin receptor to produce amylin receptor complexes. Once formed, these complexes allow binding of amylin to the receptor. Another function of RAMP3 is to complex with calcitonin receptor-like receptor (CLR) to form adrenomedullin receptors $(15,58)$. Because the RAMP family plays such an important role in the transport and modulation of GPCRs, there have been extensive pharmacological studies aimed at examining RAMPs as potential sites for modulating GPCRs for the sake of disease treatment. Though much is known about the function of this protein, little has been reported on the specific impact of RAMP3 in the control of intake and energy balance.

In the present study, if individual analyses are excluded, RAMP3 was found to be upregulated by glucose and alternatively downregulated by HFCS and fructose. Although not much is known about the role of RAMP3 in sugar metabolism, it is 
known that RAMP3 is involved in amylin processing. It is also known that CCK and amylin have similar metabolic actions such as slowing gastric emptying. Because the trends in gene expression for RAMP3 are similar to those observed with CCK, upregulation by glucose and downregulation by fructose, it is reasonable to assume that sugars have the same implications on RAMP3 expression as they do on CCK. That is to say perhaps RAMP3, upstream on the amylin pathway, triggers the same metabolic consequences as CCK.

\section{Tumor Necrosis Factor}

Tumor Necrosis Factor- $\alpha(\mathrm{TNF}-\alpha)$ is an inflammatory cytokine found in the hypothalamus. TNF plays in active role in inflammation and obesity and is involved in lipid metabolism regulation, adipocyte differentiation, and insulin sensitivity (60). TNF has been shown to interact with well-known satiety signals including leptin. Huypens has proposed a model for TNF that suggests the gene has a role in the regulation of the inverse relationship between ADIPOQ and leptin (61).

Glucose, sucrose, and fructose consumption all resulted in an upregulation of TNF expression in the hypothalamus. Recently much of the work surrounding possible causes of obesity has been centered on inflammation and the impact sugar has on inflammation (62). TNF is an important inflammatory cytokine and because sugar has been shown to cause inflammation, these results are as expected. However, it is unclear as to why HFCS did not result in upregulation as well.

Wang suggests that once animals that have been made obese with a high fat diet are switched to a chow diet, the resulting elevated TNF expression does not 
return to levels of control (62). The importance of this finding here is that even if these animals were removed from the sugar diet they may still suffer from elevations of this inflammatory peptide. In the future a longer term study which examines TNF levels following removal of sugar access from sugar-induced obese rats may provide insight into this subject.

\section{Thyrotropin Releasing Hormone}

Thyrotropin- releasing hormone (TRH), also called Thyrotropin- releasing factor (TRF), is produced in the PVN of the hypothalamus and functions to stimulate the release of thyroid stimulating hormone and prolactin from the anterior pituitary. TRH is an anorectic hormone.

The mechanism of TRH action on appetite regulation is not yet fully understood (63). Leptin has been found to have direct and indirect (through activating POMC neurons that in turn release $\alpha \mathrm{MSH}$ to stimulate $\mathrm{TRH}$ ) effects on stimulation of TRH synthesis (65).

Compared to control, TRH gene expression is upregulated in animals given access to fructose. These results are consistent with the long-recognized role of fructose promoting increases in uric acid, leading to increased risk of gout (a disease associated with hypothyroidism) (78).

NPY also acts on TRH as an inhibitor through activation of NPY receptors on the TRH neurons (66). Here however this association could not be evaluated because results for NPY were not replicated between the array and verification analyses. In 
the future it may be interesting to further explore the connection between NPY and TRH. 


\section{Conclusion}

Obesity has become such a significant public health concern that there is urgency to better understand its causes. Due to sugars' ability to alter hypothalamic appetite regulation, this research attempted to evaluate the hypothesis that increased intake of added sugars may be contributing to the obesity epidemic. This was a very well designed protocol as it looked at common disaccharides while also having the monosaccharaide controls. Many other studies examining HFCS fail to have fructose and/or glucose control groups. This research has shed light onto many important effects of sugar consumption and also presented the opportunity for many other follow up experiments.

It is curious that the only significant changes in gene expression that were verified in all performed assays were changes in anorectic genes. However, it should be pointed out that there are fewer known orexogenic genes. Another interesting trend in gene expression is that in the glucose fed group, the only significant changes were those of upregulations. In other words, glucose intake only resulted in the upregulation of anorectic gene expression. This might be an indicator of how glucose metabolism evolved and how glucose, being a good source of calories, tells the body that enough calories have been taken in and eating can stop.

This research laid the groundwork for many other follow up studies. First of all, a longer term sugar feeding study would allow for the examination of changes in intake following adaptation to the novelty of the sugar solutions. Laboratory rats will over eat sugar initially but will subsequently restore control-level total caloric intake. A longer duration study would examine the novelty effect of initial access to sugar 
solutions and should show that intake of treatment groups will, over time, more closely resemble controls. Once intake is 'leveled off,' evaluation of gene expression in the hypothalamus will provide insight into how gene expression changes with longer term access. Also, depending on the length of access, by the end of an extended feeding study the animals may become obese. It would be interesting to compare changes in hypothalamic gene expression between both the long term study obese animals with the present study lean animals.

With a longer term study it might also be interesting to provide animals with different doses of sugars and also take samples at more time intervals. Assuming animals are sacrificed and hypothalamic tissue analyzed throughout the study, the varied doses will allow for the examination of thresholds at which changes become significant. This would apply to humans who consume sugar sweetened beverages at different levels of consumption.

While doing this long term study, or even in a short term study as this was, sampling plasma continuously would allow for a more real time analysis of change in plasma TG as well as glucose. In the present study, there were no changes observed in insulin and glucose. Continuous sampling would allow for the measure of these in as they respond to intake.

Finally in future studies it would be interesting to examine changes in protein levels of the hypothalamic genes of interest. The fact that a gene is upregulated does not necessarily mean the protein will be expressed in greater amounts. Measuring changes in protein will allow for a complete examination of the impact of sugars on gene expression in the appetite center of the brain, the hypothalamus. 
Figure 1. Relationship between fructose intake and prevalence of overweight and obesity.

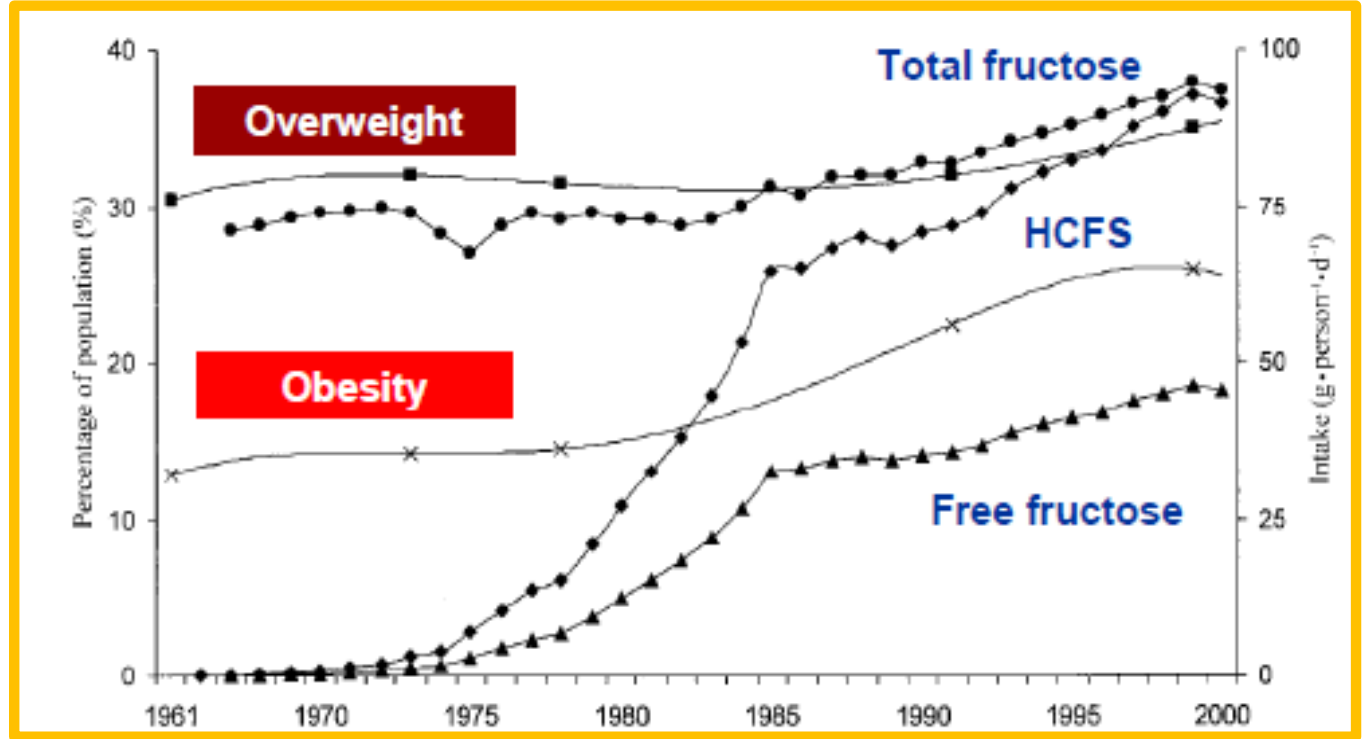

Plotted above are the average changes in intake of fructose (free and total) and HFCS over time (in years) as well as the average changes in the \% of the population classified as either overweight or obese during that same period. (Adapted from Bray et al., 2004) 
Figure 2. Metabolism of glucose and fructose

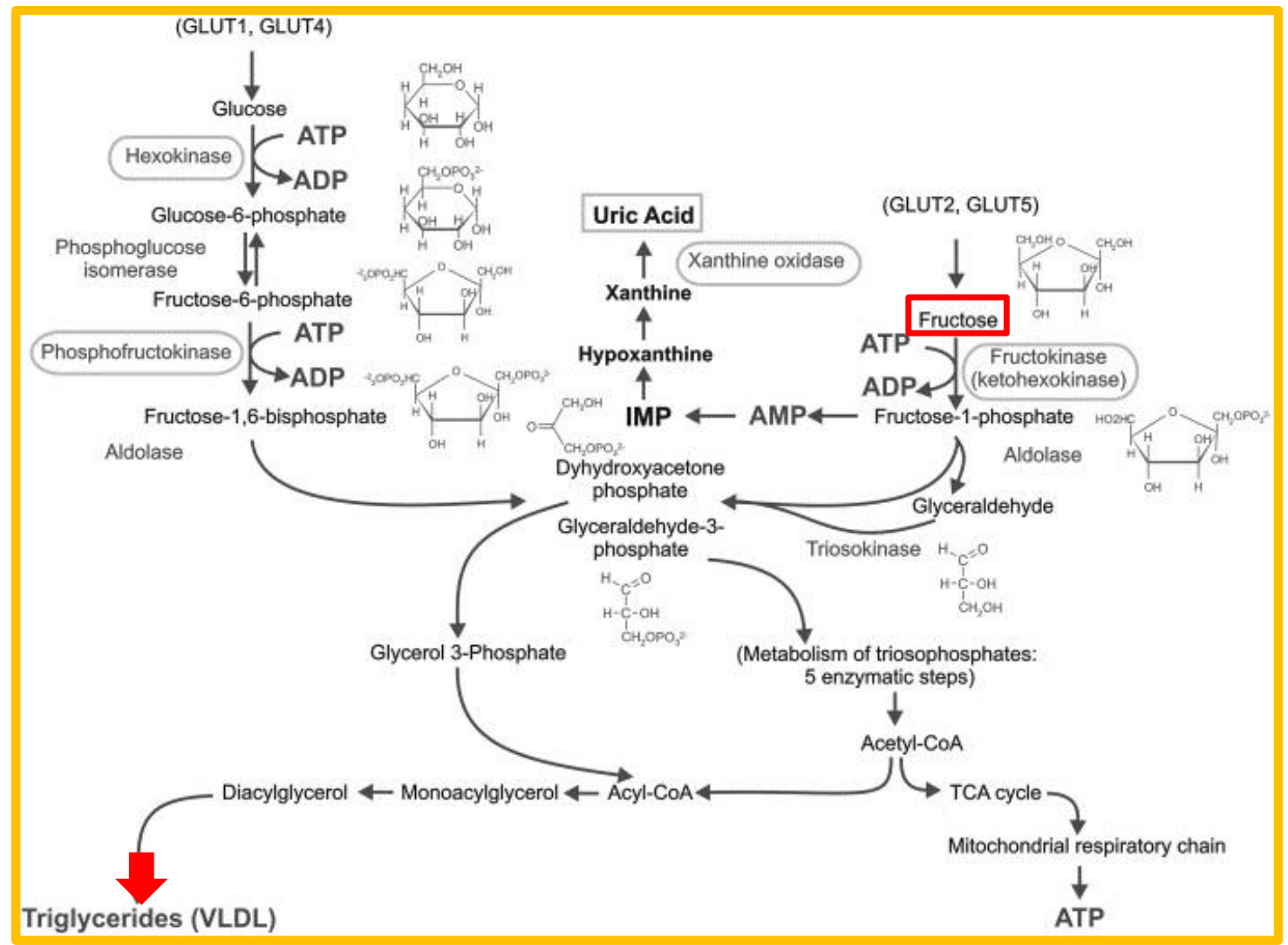

Comparison of the metabolism of fructose and glucose. The red arrow indicates where fructose enters the liver cell via the GLUT5 transporter and feeds into the glycolysis pathway. Fructose has less control points and feeds directly into G3P (glucose-3-phosphate). The red box surrounds the results of the TCA cycle which is the formation of TG. Adapted from Johnson et al., 2009 (79). 
Figure 3. Hypothalamic sectioning

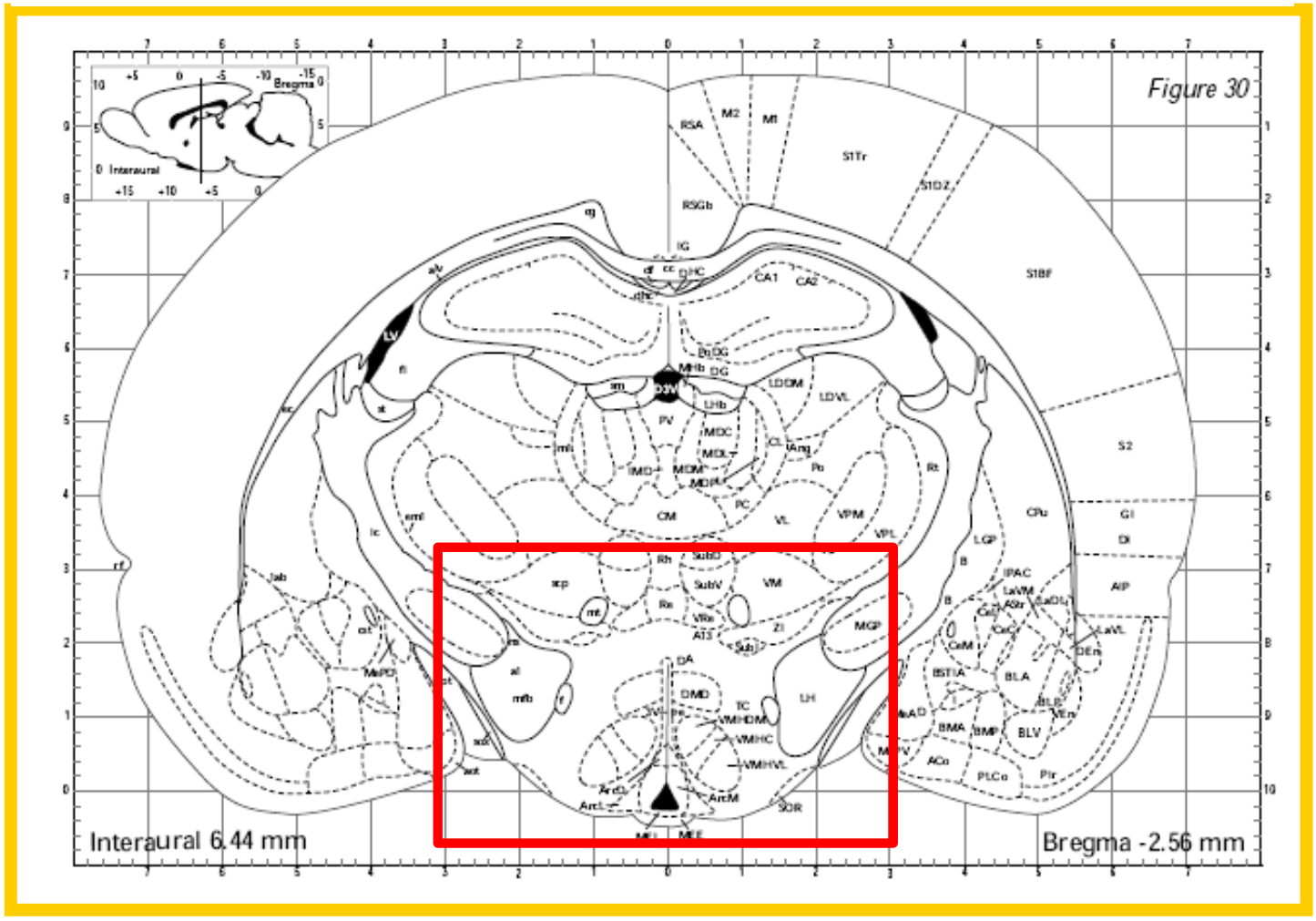

Sectioned rat brain showing region of tissue collected for measure of changes in gene expression. Area of collection is boxed in red. Regions include VMN, DMN, PVN, arcuate nucleus and median eminence. Adapted from Paxinos and Watson, 1986 (80). 
Table 1. Primers used for pooled and individual verification RT-PCR analyses.

\begin{tabular}{|c|c|c|c|c|c|}
\hline Gene & Accession Number & $\begin{array}{l}\text { Product } \\
\text { Length } \\
\text { (BP) }\end{array}$ & $\begin{array}{l}\text { TaOpt } \\
\left({ }^{\circ} \mathbf{C}\right)\end{array}$ & Sense Primer & Anti-sense Primer \\
\hline ADIPOQ & NM_144744 & 194 & 51 & $\begin{array}{l}\text { TTGAGAGGTTGATTGTAT } \\
\mathrm{T}\end{array}$ & $\begin{array}{l}\text { AGTGGCAATATAGTTGTA } \\
\text { AT }\end{array}$ \\
\hline ADRA2b & NM_138505 & 114 & 53.5 & TACTCTCATCATCССТТTC & $\begin{array}{l}\text { ATGGAGGAGGTACAGAA } \\
\text { G }\end{array}$ \\
\hline AGRP & XM_574228 & 97 & 57.6 & $\begin{array}{l}\text { GAGTTCTCAGGTCTAAGT } \\
\text { CT }\end{array}$ & GTGGATCTAGCACCTCTG \\
\hline APOA4 & NM_012737 & 129 & 58.9 & CTCCATACCAAAGTCTCC & CTTGTTCAGGTCTTCCAG \\
\hline B ACTIN & NM_031144 & 165 & 56.5 & $\begin{array}{l}\text { TGTCACCAACTGGGACGA } \\
\text { TA }\end{array}$ & $\begin{array}{l}\text { GGGGTGTTGAAGGTCTCA } \\
\text { AA }\end{array}$ \\
\hline $\mathrm{CCK}$ & NM_012829 & 133 & 53 & $\begin{array}{l}\text { GCGTTTATTTATTAAGTC } \\
\text { C }\end{array}$ & ATAGCATAGCAACATTAG \\
\hline CLPS & NM_013139 & 83 & 58.9 & CCTTGTTGTTCTGCTTGTA & CGTCCTCCAGGTTGATAA \\
\hline $\mathrm{CRH}$ & NM_031019 & 158 & 51 & TGGAGATTATCGGGAAAT & $\begin{array}{l}\text { TACATCTTCTATGCTTCA } \\
\text { AG }\end{array}$ \\
\hline DRD1A & NM_012546 & 75 & 54.5 & $\begin{array}{l}\text { CTCAACCCTCTTAGGATG } \\
\text { CTACA }\end{array}$ & $\begin{array}{l}\text { TTGTTGTTAATGCTCACC } \\
\text { GTCTC }\end{array}$ \\
\hline GAPDH & NM_017008 & 92 & 56 & ТСССАТТСТТССАССТТТ & $\begin{array}{l}\text { TAGCCATATTCATTGTCA } \\
\text { TACC }\end{array}$ \\
\hline GH1 & NM_001034848 & 88 & 51 & $\begin{array}{l}\text { CAAGCAAACCTATGACA } \\
\text { A }\end{array}$ & CTTCTTGAAGCAGGAGAG \\
\hline IAPP & NM_012586 & 92 & 56.2 & AACTTCTTGGTTCGCTCC & TCTGCCACATTCCTCTTC \\
\hline LDHA & NM_017025 & 112 & 54.2 & $\begin{array}{l}\text { TTGTTGATGTCATAGAAG } \\
\text { A }\end{array}$ & GCAGTCACACTATAATCT \\
\hline NPY & NM_012614 & 89 & 53.9 & $\begin{array}{l}\text { AATGAGAGAAAGCACAG } \\
\text { AAA }\end{array}$ & $\begin{array}{l}\text { AAGTCAGGAGAGCAAGT } \\
\mathrm{T}\end{array}$ \\
\hline RAMP3 & NM_020100 & 109 & 54.6 & CAAGGTCATCTGGAAGGT & $\begin{array}{l}\text { GACTCCTAACAACTCCAT } \\
\text { TC }\end{array}$ \\
\hline RPLP1 & NM_001007604 & 81 & 53.5 & $\begin{array}{l}\text { GAAGAATCCGAGGATGA } \\
\text { CA }\end{array}$ & $\begin{array}{l}\text { CAGGTTCAGCTCTTTATT } \\
\text { GG }\end{array}$ \\
\hline TNF & NM_012675 & 318 & 61 & $\begin{array}{l}\text { GGCAGGTCTACTTTGGAG } \\
\text { TCATTGC }\end{array}$ & $\begin{array}{l}\text { ACATTCGGGGATCCAGTG } \\
\text { AGCTCCG }\end{array}$ \\
\hline TRH & NM_013046 & 75 & 59.7 & $\begin{array}{l}\text { AAAGACATTGAAGCTGA } \\
\text { AGAGAGG }\end{array}$ & GGGGTGCTGTCGTTTGTG \\
\hline UCN & NM_019150 & 75 & 60.6 & AGCAGAACCGCATCATAT & AAAGGGTCAAGGCTTTCT \\
\hline
\end{tabular}

Primers were designed using Beacon Designer 7 unless otherwise noted in Methods section. TaOpt determined empirically. 
Table 2. Average body weight of rats following 24 hour sugar access

\begin{tabular}{|r|r|r|r|r|r|}
\hline & Control & Glucose & Sucrose & \multicolumn{1}{c|}{ HFCS } & Fructose \\
\hline Average BW (g) & $319.4^{\mathrm{a}}$ & $323.6^{\mathrm{a}}$ & $319.1^{\mathrm{a}}$ & $314.5^{\mathrm{a}}$ & $321.8^{\mathrm{a}}$ \\
\hline
\end{tabular}

Average body weight in grams. Rats were weighed just prior to sacrifice. Averages that share a common superscript are not different from one another $(\mathrm{p}>0.05)$. 
Table 3. Mean chow and sugar intake following 24 hour access to sugar solutions

Grams

Fructose

Glucose

Total sugar

Chow

\begin{tabular}{|l|l|l|l|l|} 
Control & \multicolumn{1}{c}{ Glucose } & \multicolumn{1}{c}{ Sucrose } & \multicolumn{1}{c}{ HFCS } & \multicolumn{1}{c|}{ Fructose } \\
\hline & & $6.20^{\mathrm{b}}$ & $7.28^{\mathrm{b}}$ & $10.96^{\mathrm{a}}$ \\
\hline & $9.83^{\mathrm{a}}$ & $6.20^{\mathrm{b}}$ & $5.96^{\mathrm{b}}$ & \\
\hline & $9.83^{\mathrm{b}}$ & $12.41^{\mathrm{ab}}$ & $13.23^{\mathrm{a}}$ & $10.96^{\mathrm{ab}}$ \\
\hline $28.32^{\mathrm{a}}$ & $21.36^{\mathrm{b}}$ & $19.26^{\mathrm{bc}}$ & $17.90^{\mathrm{c}}$ & $21.41^{\mathrm{b}}$ \\
\hline
\end{tabular}

kCal

Chow

Sugar

Total

$\% \mathrm{kCal}$ as sugar

\begin{tabular}{|l|l|l|l|l|}
\hline $96.57^{\mathrm{a}}$ & $72.85^{\mathrm{b}}$ & $65.69^{\mathrm{bc}}$ & $61.04^{\mathrm{c}}$ & $73.02^{\mathrm{b}}$ \\
\hline & $39.32^{\mathrm{b}}$ & $49.62^{\mathrm{ab}}$ & $52.94^{\mathrm{a}}$ & $43.83^{\mathrm{ab}}$ \\
\hline $96.57^{\mathrm{b}}$ & $112.17^{\mathrm{a}}$ & $115.31^{\mathrm{a}}$ & $113.98^{\mathrm{a}}$ & $116.85^{\mathrm{a}}$ \\
\hline & $33.65 \%^{\mathrm{b}}$ & $43.00 \%^{\mathrm{a}}$ & $46.17 \%^{\mathrm{a}}$ & $37.31 \%^{\mathrm{ab}}$ \\
\hline
\end{tabular}

Rats were given 24 hour access to a sugar solution as well as water and chow. Control animals had access to chow and water only. Averages of each measurement that share a common superscript are not different from one another $(\mathrm{p}>0.05)$. 
Table 4. Results of plasma analyses

\section{Group}

Triglyceride (mg/dL)

Glucose (mg/dL)

Insulin $(\mathbf{n g} / \mathbf{m L})$

\begin{tabular}{|r|r|r|r|r|}
\multicolumn{5}{c}{ Group } \\
\multicolumn{1}{c|}{ Control } & \multicolumn{1}{c|}{ Glucose } & \multicolumn{1}{c|}{ Sucrose } & \multicolumn{1}{c|}{ HFCS } & \multicolumn{1}{c|}{ Fructose } \\
\hline $148.21^{\mathrm{b}}$ & $154.11^{\mathrm{b}}$ & $175.80^{\mathrm{b}}$ & $224.02^{\mathrm{a}}$ & $283.88^{\mathrm{ab}}$ \\
\hline $166.58^{\mathrm{a}}$ & $163.72^{\mathrm{a}}$ & $157.80^{\mathrm{a}}$ & $167.84^{\mathrm{a}}$ & $161.86^{\mathrm{a}}$ \\
\hline $4.51^{\mathrm{a}}$ & $3.42^{\mathrm{a}}$ & $4.27^{\mathrm{a}}$ & $4.01^{\mathrm{a}}$ & $4.65^{\mathrm{a}}$ \\
\hline
\end{tabular}

Changes in plasma TG, glucose and insulin following 24 hour access to sugar solutions. Plasma was collected from trunkal blood at the time of sacrifice. Triglycerides were measured with the Dimension clinical chemistry system with a Flex reagent cartridge (Siemens Healthcare Diagnostics, Newark, DE) using a Dade Behring Dimension Xpand automated system. Glucose was measured enzymatically (Smith-Kline Beecham Laboratories, Brentford, Middlesex, UK). Insulin was measured by ELISA (LINCOplex; LINCO Research, St. Charles, MO). Averages of each measurement that share a common superscript are not different from one another $(\mathrm{p}>0.05)$. 
Table 5. Cycle threshold (Ct) of housekeepers

\begin{tabular}{|c|c|c|c|c|c|}
\hline & Control & Glucose & Sucrose & HFCS & Fructose \\
\hline$\beta$-Actin & $19.11^{\mathrm{a}}$ & $16.08^{\text {cd }}$ & $15.74^{\mathrm{d}}$ & $17.60^{\mathrm{b}}$ & $16.47^{c}$ \\
\hline GAPDH & $16.90^{\mathrm{ab}}$ & $16.95^{\mathrm{ab}}$ & $16.55^{\mathrm{b}}$ & $17.01^{\mathrm{ab}}$ & $17.05^{\mathrm{a}}$ \\
\hline RPLP1 & $17.57^{\mathrm{a}}$ & $17.88^{\mathrm{a}}$ & $17.53^{\mathrm{a}}$ & $17.55^{\mathrm{a}}$ & $17.56^{\mathrm{a}}$ \\
\hline $\mathbf{N}$ & 5 & 8 & 5 & 5 & 8 \\
\hline
\end{tabular}

Multiple housekeepers were analyzed and the one with the least variation between experimental groups and the lowest $\mathrm{Ct}$ was selected. Presented are the cycle thresholds $(\mathrm{Ct})$ of RT-PCR using each housekeeper primer set and pooled hypothalamic cDNA from each experimental group. Primer sequence can be found in Table 1. Averages of each measurement that share a common superscript are not different from one another $(\mathrm{p}>0.05)$. 
Table 6. List of significant fold changes

\begin{tabular}{|l|l|r|r|r|r|}
\hline \multicolumn{2}{|c|}{ Gene Name } & \multicolumn{4}{c|}{ Group } \\
\hline Symbol & \multicolumn{1}{|c|}{ Glucose } & Sucrose & HFCS & Fructose \\
\hline Adipoq & Adiponectin & 3.54 & 1.01 & 1.33 & 2.33 \\
\hline Adra2b & Adrenergic, alpha-2B-, receptor & 1.16 & 0.86 & 0.35 & 0.48 \\
\hline Agrp & Agouti related protein homolog (mouse) & 1.26 & 0.96 & 1.98 & 1.05 \\
\hline Apoa4 & Apolipoprotein A-IV & 0.86 & 0.28 & 1.15 & 0.58 \\
\hline Cck & Cholecystokinin & 1.98 & 1.23 & 1.39 & 0.63 \\
\hline Clps & Colipase, pancreatic & 1.56 & 1.48 & 1.56 & 0.98 \\
\hline Crh & Corticotropin releasing hormone & 0.87 & 0.76 & 0.48 & 1.21 \\
\hline Drd1a & Dopamine receptor D1A & 0.83 & 0.70 & 2.07 & 1.08 \\
\hline Gh1 & Growth hormone 1 & 3.27 & 1.01 & 1.20 & 1.09 \\
\hline Iapp & Islet amyloid polypeptide & 2.00 & 1.11 & 1.20 & 2.28 \\
\hline Il1a & Interleukin 1 alpha & 1.19 & 1.75 & 0.95 & 1.01 \\
\hline Il6 & Interleukin 6 & 1.12 & 1.51 & 0.83 & 0.92 \\
\hline Ins2 & Insulin 2 & 0.66 & 0.97 & 0.47 & 0.80 \\
\hline Nmu & Neuromedin U & 1.11 & 0.38 & 1.30 & 1.08 \\
\hline NPY & Neuropeptide Y & 1.20 & 1.03 & 2.27 & 1.01 \\
\hline Ntrk1 & Neurotrophic tyrosine kinase, receptor, 1 & 0.94 & 1.20 & 1.85 \\
\hline Ramp3 & Receptor activity modifying protein 3 & 1.32 & 1.09 & 0.44 & 0.52 \\
\hline Tnf & Tumor necrosis factor & 1.65 & 1.39 & 1.04 & 1.25 \\
\hline Trh & Thyrotropin releasing hormone & 0.55 & 0.77 & 0.43 & 1.22 \\
\hline Ucn & Urocortin & 4.08 & 1.01 & 1.44 & 1.09 \\
\hline
\end{tabular}

Presented in the right hand columns of this table are the fold changes in appetite regulating genes. Highlighted in yellow or red are those changes that were considered "significant." In order to be considered "significant" a fold change needed to be downregulated (red) by $50 \%$ or more (fold change $\leq 0.5$ ) or upregulated (yellow) by $150 \%$ or more (fold change $\geq 1.5$ ) following sugar access. Fold change was calculated Fold change was calculated as $2^{\wedge}(-\mathrm{ddCt})$. 
Table 7. Summary of analysis used to determine the effect of sugar solution access on hypothalamic ADIPOQ.

\begin{tabular}{|l|l|l|l|l|l|l|}
\hline & & Control & Glucose & Sucrose & \multicolumn{1}{c|}{ HFCS } & Fructose \\
\hline \multirow{3}{*}{ PCR Array } & $\mathbf{C t}$ & 37.12 & 33.54 & 36.01 & 34.88 & 33.90 \\
\cline { 2 - 7 } & Fold change & $1.00^{\mathrm{b}}$ & $3.74^{\mathrm{a}}$ & $1.02^{\mathrm{b}}$ & $1.34^{\mathrm{b}}$ & $2.36^{\mathrm{ab}}$ \\
\cline { 2 - 7 } & $\mathbf{N}$ & 5 & 8 & 5 & 5 & 8 \\
\hline
\end{tabular}

Results of PCR array analysis of ADIPOQ expression in the hypothalamus of animals given 24 hour access to sugar solutions. Rat Obesity RT ${ }^{2}$ Profiler ${ }^{\mathrm{TM}}$ PCR Array (PARN-017A, SABiosciences) was used to obtain estimates of changes to ADIPOQ. PCR array was performed on pooled hypothalamic tissue from all animals in each group. Averages of each measurement that share a common superscript are not different from one another $(\mathrm{p}>0.05)$. 
Table 8. Summary of analyses used to determine the effect of sugar solution access on hypothalamic ADRA2b expression

\begin{tabular}{|l|l|r|r|r|r|r|}
\hline & & Control & Glucose & Sucrose & \multicolumn{1}{c|}{ HFCS } & Fructose \\
\hline \multirow{3}{*}{ PCR Array } & $\mathbf{C t}$ & 32.69 & 32.84 & 32.93 & 34.48 & 33.87 \\
\cline { 2 - 7 } & Fold change & $1.00^{\mathrm{ab}}$ & $1.17^{\mathrm{a}}$ & $0.86^{\mathrm{b}}$ & $0.35^{\mathrm{c}}$ & $0.48^{\mathrm{c}}$ \\
\cline { 2 - 8 } & $\mathbf{N}$ & 5 & 8 & 5 & 5 & 8 \\
\hline \multirow{2}{*}{$\begin{array}{l}\text { Pooled } \\
\text { verification }\end{array}$} & $\mathbf{C t}$ & 33.14 & 29.59 & 29.55 & 33.67 & 32.43 \\
\cline { 2 - 7 } & Fold change & $1.00^{\mathrm{c}}$ & $14.61^{\mathrm{a}}$ & $11.80^{\mathrm{b}}$ & $0.69^{\mathrm{c}}$ & $1.63^{\mathrm{c}}$ \\
\cline { 2 - 7 } & $\mathbf{N}$ & 5 & 8 & 5 & 5 & 8 \\
\hline
\end{tabular}

Results of two analyses of ADRA2b expression in the hypothalamus of animals given 24 hour access to sugar solutions. Rat Obesity RT² Profiler ${ }^{\mathrm{TM}}$ PCR Array (PARN017A, SABiosciences) was used to obtain initial estimates of changes to ADRA2b. Pooled verification was then performed using RT-PCR and primers designed in house. Primer sequences for pooled verification assays are found in Table 1. PCR array and pooled verification assays were performed on pooled hypothalamic tissue from all animals in each group. Averages of each measurement that share a common superscript are not different from one another $(\mathrm{p}>0.05)$. 
Table 9. Summary of the three analyses used to determine the effect of sugar solution access on hypothalamic AGRP.

\begin{tabular}{|c|c|c|c|c|c|c|}
\hline & & Control & Glucose & Sucrose & HFCS & Fructose \\
\hline \multirow[t]{3}{*}{ PCR Array } & $\mathbf{C t}$ & 26.59 & 26.62 & 26.67 & 25.87 & 26.64 \\
\hline & Fold change & $1.00^{\mathrm{b}}$ & $1.27^{\mathrm{b}}$ & $0.96^{\mathrm{b}}$ & $1.99^{\mathrm{a}}$ & $1.06^{\mathrm{b}}$ \\
\hline & $\mathbf{N}$ & 5 & 8 & 5 & 5 & 8 \\
\hline \multirow{3}{*}{$\begin{array}{l}\text { Pooled } \\
\text { verification }\end{array}$} & $\mathbf{C t}$ & 27.72 & 27.35 & 28.43 & 26.87 & 26.62 \\
\hline & Fold change & $1.00^{\mathrm{a}}$ & $1.66^{\mathrm{a}}$ & $0.62^{\mathrm{a}}$ & $1.80^{\mathrm{a}}$ & $2.53^{\mathrm{a}}$ \\
\hline & $\mathbf{N}$ & 5 & 8 & 5 & 5 & 8 \\
\hline \multirow{3}{*}{$\begin{array}{l}\text { Individual } \\
\text { verification }\end{array}$} & $\mathbf{C t}$ & 34.84 & 35.93 & 35.94 & 31.04 & 39.72 \\
\hline & Fold change & $1.00^{\mathrm{b}}$ & $1.37^{\mathrm{b}}$ & $0.74^{\mathrm{b}}$ & $32.22^{\mathrm{a}}$ & $*$ \\
\hline & $\mathbf{N}$ & 4 & 4 & 4 & 4 & 4 \\
\hline
\end{tabular}

Results of three analyses of AGRP expression in the hypothalamus of animals given 24 hour access to sugar solutions. Rat Obesity RT² Profiler ${ }^{\mathrm{TM}}$ PCR Array (PARN017A, SABiosciences) was used to obtain initial estimates of changes to AGRP. Pooled verification, followed by individual verification, was then performed using RT-PCR and primers designed in house. Primer sequences for pooled and individual verification assays are found in Table 1 . PCR array and pooled verification assays were performed on pooled hypothalamic tissue from all animals in each group. Individual verification was performed on individual hypothalamic tissue from four rats from each group. Averages of the four individual assays are presented. Averages of each measurement that share a common superscript are not different from one another ( $\mathrm{p}>0.05)$.

* Mean threshold cycle was above cutoff value of 36 cycles. As a result, data from this group was not included. 
Table 10. Summary of analysis used to determine the effect of sugar solution access on hypothalamic APOA4.

\begin{tabular}{|l|l|l|l|l|l|l|}
\hline & & Control & Glucose & Sucrose & \multicolumn{1}{|c|}{ HFCS } & Fructose \\
\hline PCR Array & $\mathbf{C t}$ & 31.81 & 32.39 & 33.68 & 31.87 & 32.73 \\
\cline { 2 - 7 } & Fold change & $1.00^{\mathrm{a}}$ & $0.86^{\mathrm{ab}}$ & $0.30^{\mathrm{c}}$ & $1.15^{\mathrm{a}}$ & $0.59^{\mathrm{b}}$ \\
\cline { 2 - 7 } & $\mathbf{n}$ & 5 & 8 & 5 & 5 & 8 \\
\hline
\end{tabular}

Results of PCR array analysis of APOA4 expression in the hypothalamus of animals given 24 hour access to sugar solutions. Rat Obesity RT ${ }^{2}$ Profiler $^{\mathrm{TM}}$ PCR Array (PARN-017A, SABiosciences) was used to obtain estimates of changes to APOA4. PCR array was performed on pooled hypothalamic tissue from all animals in each group. Averages of each measurement that share a common superscript are not different from one another $(\mathrm{p}>0.05)$. 
Table 11. Summary of the three analyses used to determine the effect of sugar solution access on hypothalamic CCK.

\begin{tabular}{|l|l|l|l|l|l|l|}
\hline & & Control & Glucose & Sucrose & \multicolumn{1}{|c|}{ HFCS } & Fructose \\
\hline \multirow{4}{*}{ PCR Array } & $\mathbf{C t}$ & 24.19 & 23.57 & 23.92 & 23.98 & 24.98 \\
\cline { 2 - 7 } & Fold change & $1.00^{\mathrm{d}}$ & $1.98^{\mathrm{a}}$ & $1.23^{\mathrm{c}}$ & $1.39^{\mathrm{b}}$ & $0.63^{\mathrm{e}}$ \\
\cline { 2 - 7 } & $\mathbf{N}$ & 5 & 8 & 5 & 5 & 8 \\
\hline \multirow{3}{*}{$\begin{array}{l}\text { Pooled } \\
\text { verification }\end{array}$} & $\mathbf{C t}$ & 21.86 & 21.27 & 21.78 & 21.82 & 23.17 \\
\cline { 2 - 8 } & $\mathbf{F o l d ~ c h a n g e ~}$ & $1.00^{\mathrm{b}}$ & $1.87^{\mathrm{a}}$ & $1.06^{\mathrm{b}}$ & $1.01^{\mathrm{b}}$ & $0.40^{\mathrm{c}}$ \\
\cline { 2 - 8 } & $\mathbf{N}$ & 5 & 8 & 5 & 5 & 8 \\
\hline \multirow{3}{*}{$\begin{array}{l}\text { Individual } \\
\text { verification }\end{array}$} & $\mathbf{C t}$ & 28.75 & 27.10 & 24.13 & 28.46 & 29.06 \\
\cline { 2 - 8 } & $\mathbf{F o l d ~ c h a n g e ~}$ & $1.00^{\mathrm{c}}$ & $6.38^{\mathrm{a}}$ & $2.83^{\mathrm{b}}$ & $1.34^{\mathrm{c}}$ & $1.12^{\mathrm{c}}$ \\
\cline { 2 - 8 } & $\mathbf{N}$ & 4 & 4 & 4 & 4 & 4 \\
\hline
\end{tabular}

Results of three analyses of CCK expression in the hypothalamus of animals given 24 hour access to sugar solutions. Rat Obesity RT2 Profiler ${ }^{\mathrm{TM}}$ PCR Array (PARN-017A, SABiosciences) was used to obtain initial estimates of changes to CCK. Pooled verification, followed by individual verification, was then performed using RT-PCR and primers designed in house. Primer sequences for pooled and individual verification assays are found in Table 1. PCR array and pooled verification assays were performed on pooled hypothalamic tissue from all animals in each group. Individual verification was performed on individual hypothalamic tissue from four rats from each group. Averages of the four individual assays are presented. Averages of each measurement that share a common superscript are not different from one another $(\mathrm{p}>0.05)$. 
Table 12. Summary of analysis used to determine the effect of sugar solution access on hypothalamic CLPS.

\begin{tabular}{|l|l|l|l|l|l|l|}
\hline & & Control & Glucose & Sucrose & \multicolumn{1}{|c|}{ HFCS } & Fructose \\
\hline \multirow{3}{*}{ PCR Array } & $\mathbf{C t}$ & 32.77 & 32.92 & 32.49 & 32.39 & 32.22 \\
\cline { 2 - 7 } & Fold change & $1.00^{\mathrm{a}}$ & $1.09^{\mathrm{a}}$ & $1.57^{\mathrm{a}}$ & $1.59^{\mathrm{a}}$ & $1.62^{\mathrm{a}}$ \\
\cline { 2 - 7 } & $\mathbf{N}$ & 5 & 8 & 5 & 5 & 8 \\
\hline
\end{tabular}

Results of PCR array analysis of CLPS expression in the hypothalamus of animals given 24 hour access to sugar solutions. Rat Obesity RT ${ }^{2}$ Profiler $^{\mathrm{TM}}$ PCR Array (PARN-017A, SABiosciences) was used to obtain estimates of changes to CLPS. PCR array was performed on pooled hypothalamic tissue from all animals in each group. Averages of each measurement that share a common superscript are not different from one another $(\mathrm{p}>0.05)$. 
Table 13. Summary of analyses used to determine the effect of sugar solution access on hypothalamic $\mathrm{CRH}$.

\begin{tabular}{|l|l|l|l|l|l|l|}
\hline \multirow{4}{*}{ PCR Array } & Ct & \multicolumn{1}{|c|}{ Control } & Glucose & Sucrose & \multicolumn{1}{|c|}{ HFCS } & Fructose \\
\cline { 2 - 7 } & Fold change & 27.03 & 27.59 & 27.45 & 28.34 & 26.88 \\
\cline { 2 - 7 } & $\mathbf{N}$ & 5 & $8.87^{\mathrm{b}}$ & $0.76^{\mathrm{bc}}$ & $0.49^{\mathrm{c}}$ & $1.21^{\mathrm{a}}$ \\
\hline \multirow{3}{*}{$\begin{array}{l}\text { Pooled } \\
\text { verification }\end{array}$} & $\mathbf{C t}$ & 30.40 & 31.22 & 30.49 & 5 & 8 \\
\cline { 2 - 7 } & Fold change & $1.00^{\mathrm{b}}$ & $0.72^{\mathrm{c}}$ & $0.94^{\mathrm{b}}$ & $0.27^{\mathrm{d}}$ & $1.24^{\mathrm{a}}$ \\
\cline { 2 - 7 } & $\mathbf{N}$ & 5 & 8 & 5 & 5 & 8 \\
\hline
\end{tabular}

Results of two analyses of CRH expression in the hypothalamus of animals given 24

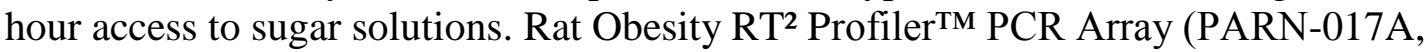
SABiosciences) was used to obtain initial estimates of changes to CRH. Pooled verification was then performed using RT-PCR and primers designed in house. Primer sequences for pooled verification assays are found in Table 1. PCR array and pooled verification assays were performed on pooled hypothalamic tissue from all animals in each group. Averages of each measurement that share a common superscript are not different from one another ( $p>0.05)$. 
Table 14. Summary of the three analyses used to determine the effect of sugar solution access on hypothalamic DRD1a.

\begin{tabular}{|c|c|c|c|c|c|c|}
\hline & & Control & Glucose & Sucrose & HFCS & Fructose \\
\hline \multirow[t]{3}{*}{ PCR Array } & $\mathbf{C t}$ & 28.87 & 29.51 & 29.41 & 28.08 & 28.87 \\
\hline & Fold change & $1.00^{\mathrm{b}}$ & $0.83^{\mathrm{bc}}$ & $0.70^{\mathrm{c}}$ & $2.07^{\mathrm{a}}$ & $1.09^{\mathrm{b}}$ \\
\hline & $\mathbf{n}$ & 5 & 8 & 5 & 5 & 8 \\
\hline \multirow{3}{*}{$\begin{array}{l}\text { Pooled } \\
\text { verification }\end{array}$} & $\mathrm{Ct}$ & 30.80 & 29.65 & 29.11 & 29.32 & 28.74 \\
\hline & Fold change & $1.00^{\mathrm{b}}$ & $2.76^{\mathrm{ab}}$ & $3.32^{\mathrm{a}}$ & $2.75^{\mathrm{ab}}$ & $4.15^{\mathrm{a}}$ \\
\hline & $\mathbf{n}$ & 5 & 8 & 5 & 5 & 8 \\
\hline \multirow{2}{*}{$\begin{array}{l}\text { Individual } \\
\text { verification }\end{array}$} & $\mathbf{C t}$ & 38.96 & 39.32 & 39.22 & 38.27 & 39.02 \\
\hline & $\mathbf{n}$ & 4 & 4 & 4 & 4 & 4 \\
\hline
\end{tabular}

Results of three analyses of DRD1a expression in the hypothalamus of animals given 24 hour access to sugar solutions. Rat Obesity RT² Profiler ${ }^{\mathrm{TM}}$ PCR Array (PARN017A, SABiosciences) was used to obtain initial estimates of changes to DRD1a. Pooled verification, followed by individual verification, was then performed using RT-PCR and primers designed in house. Primer sequences for pooled and individual verification assays are found in Table 1 . PCR array and pooled verification assays were performed on pooled hypothalamic tissue from all animals in each group. Individual verification was performed on individual hypothalamic tissue from four rats from each group. Averages of the four individual verification assays are presented. Fold change is not presented for individual verification because $\mathrm{Ct}$ was greater than 35 and thus not 'significant.' Averages of each measurement that share a common superscript are not different from one another $(\mathrm{p}>0.05)$. 
Table 15. Summary of the three analyses used to determine the effect of sugar solution access on hypothalamic GH1.

\begin{tabular}{|c|c|c|c|c|c|c|}
\hline & & Control & Glucose & Sucrose & HFCS & Fructose \\
\hline \multirow[t]{3}{*}{ PCR Array } & $\mathbf{C t}$ & 36.78 & 33.66 & 36.64 & 36.90 & 35.77 \\
\hline & Fold change & $1.00^{\mathrm{b}}$ & $3.32^{\mathrm{a}}$ & $1.02^{\mathrm{b}}$ & $1.20^{\mathrm{b}}$ & $1.11^{\mathrm{b}}$ \\
\hline & $\mathbf{n}$ & 5 & 8 & 5 & 5 & 8 \\
\hline \multirow{3}{*}{$\begin{array}{l}\text { Pooled } \\
\text { verification }\end{array}$} & $\mathrm{Ct}$ & 34.01 & 32.35 & 32.73 & 33.25 & 32.68 \\
\hline & Fold change & $1.00^{\mathrm{d}}$ & $3.93^{\mathrm{a}}$ & $2.37^{\mathrm{bc}}$ & $1.67^{\mathrm{cd}}$ & $2.54^{\mathrm{b}}$ \\
\hline & $\mathbf{n}$ & 5 & 8 & 5 & 5 & 8 \\
\hline \multirow{2}{*}{$\begin{array}{l}\text { Individual } \\
\text { verification }\end{array}$} & $\mathbf{C t}$ & 38.95 & 33.66 & 38.80 & 37.56 & 38.29 \\
\hline & $\mathbf{n}$ & 4 & 4 & 4 & 4 & 4 \\
\hline
\end{tabular}

Results of three analyses of GH1 expression in the hypothalamus of animals given 24 hour access to sugar solutions. Rat Obesity RT R Profiler $^{\mathrm{TM}}$ PCR Array (PARN-017A, SABiosciences) was used to obtain initial estimates of changes to GH1. Pooled verification, followed by individual verification, was then performed using RT-PCR and primers designed in house. Primer sequences for pooled and individual verification assays are found in Table 1 . PCR array and pooled verification assays were performed on pooled hypothalamic tissue from all animals in each group. Individual verification was performed on individual hypothalamic tissue from four rats from each group. Averages of the four individual verification assays are presented. Fold change is not presented for individual verification because $\mathrm{Ct}$ was greater than 35 and thus not 'significant.' Averages of each measurement that share a common superscript are not different from one another $(\mathrm{p}>0.05)$. 
Table 16. Summary of analyses used to determine the effect of sugar solution access on hypothalamic IAPP.

\begin{tabular}{|l|l|l|l|l|l|l|}
\hline \multirow{4}{*}{ PCR Array } & Ct & Control & Glucose & Sucrose & \multicolumn{1}{|c|}{ HFCS } & Fructose \\
\cline { 2 - 7 } & Fold change & 35.82 & 34.37 & 35.42 & 35.75 & 33.93 \\
\cline { 2 - 7 } & $\mathbf{n}$ & 8 & $2.24^{\mathrm{a}}$ & $1.13^{\mathrm{a}}$ & $1.20^{\mathrm{a}}$ & $2.39^{\mathrm{a}}$ \\
\hline \multirow{3}{*}{$\begin{array}{l}\text { Pooled } \\
\text { verification }\end{array}$} & $\mathbf{C t}$ & 34.82 & 32.86 & 8 & 8 & 8 \\
\cline { 2 - 7 } & Fold change & $1.00^{\mathrm{c}}$ & $4.83^{\mathrm{a}}$ & $1.36^{\mathrm{c}}$ & $1.49^{\mathrm{c}}$ & $2.98^{\mathrm{b}}$ \\
\cline { 2 - 7 } & $\mathbf{n}$ & 5 & 8 & 5 & 5 & 8 \\
\hline
\end{tabular}

Results of two analyses of IAPP expression in the hypothalamus of animals given 24

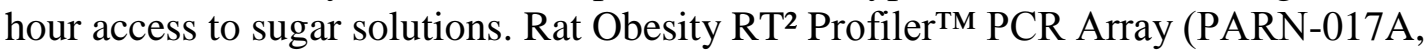
SABiosciences) was used to obtain initial estimates of changes to IAPP. Pooled verification was then performed using RT-PCR and primers designed in house. Primer sequences for pooled verification assays are found in Table 1. PCR array and pooled verification assays were performed on pooled hypothalamic tissue from all animals in each group. Averages of each measurement that share a common superscript are not different from one another ( $p>0.05)$. 
Table 17. Summary of the three analyses used to determine the effect of sugar solution access on hypothalamic NPY.

\begin{tabular}{|l|l|l|l|l|l|l|}
\hline & & Control & Glucose & Sucrose & \multicolumn{1}{|c|}{ HFCS } & Fructose \\
\hline \multirow{4}{*}{ PCR Array } & $\mathbf{C t}$ & 25.80 & 25.98 & 25.77 & 24.88 & 25.90 \\
\cline { 2 - 7 } & Fold change & $1.00^{\mathrm{b}}$ & $1.14^{\mathrm{b}}$ & $1.03^{\mathrm{b}}$ & $2.27^{\mathrm{a}}$ & $1.02^{\mathrm{b}}$ \\
\cline { 2 - 7 } & $\mathbf{n}$ & 5 & 8 & 5 & 5 & 8 \\
\hline \multirow{3}{*}{$\begin{array}{l}\text { Pooled } \\
\text { verification }\end{array}$} & $\mathbf{C t}$ & 24.69 & 26.03 & 25.10 & 24.72 & 25.13 \\
\cline { 2 - 8 } & Fold change & $1.00^{\mathrm{a}}$ & $0.49^{\mathrm{c}}$ & $0.73^{\mathrm{b}}$ & $0.96^{\mathrm{a}}$ & $0.74^{\mathrm{b}}$ \\
\cline { 2 - 7 } & $\mathbf{n}$ & 5 & 8 & 5 & 5 & 8 \\
\hline \multirow{3}{*}{$\begin{array}{l}\text { Individual } \\
\text { verification }\end{array}$} & $\mathbf{C t}$ & 27.01 & 26.80 & 26.25 & 25.03 & 27.06 \\
\cline { 2 - 7 } & Fold change & $1.00^{\mathrm{c}}$ & $1.61^{\mathrm{b}}$ & $1.24^{\mathrm{c}}$ & $3.52^{\mathrm{a}}$ & $1.11^{\mathrm{c}}$ \\
\cline { 2 - 8 } & $\mathbf{n}$ & 4 & 4 & 4 & 4 & 4 \\
\hline
\end{tabular}

Results of three analyses of NPY expression in the hypothalamus of animals given 24 hour access to sugar solutions. Rat Obesity RT² Profiler ${ }^{\mathrm{TM}}$ PCR Array (PARN-017A, SABiosciences) was used to obtain initial estimates of changes to NPY. Pooled verification, followed by individual verification, was then performed using RT-PCR and primers designed in house. Primer sequences for pooled and individual verification assays are found in Table 1. PCR array and pooled verification assays were performed on pooled hypothalamic tissue from all animals in each group. Individual verification was performed on individual hypothalamic tissue from four rats from each group. Averages of the four individual assays are presented. Averages of each measurement that share a common superscript are not different from one another $(\mathrm{p}>0.05)$. 
Table 18. Summary of the three analyses used to determine the effect of sugar solution access on hypothalamic RAMP3.

\begin{tabular}{|c|c|c|c|c|c|c|}
\hline & & Control & Glucose & Sucrose & HFCS & Fructose \\
\hline \multirow[t]{3}{*}{ PCR Array } & $\mathbf{C t}$ & 25.99 & 25.95 & 25.88 & 27.43 & 27.05 \\
\hline & Fold change & $1.00^{\mathrm{b}}$ & $1.32^{\mathrm{a}}$ & $1.09^{\mathrm{ab}}$ & $0.44^{\mathrm{c}}$ & $0.53^{\mathrm{c}}$ \\
\hline & $\mathbf{N}$ & 5 & 8 & 5 & 5 & 8 \\
\hline \multirow{3}{*}{$\begin{array}{l}\text { Pooled } \\
\text { verification }\end{array}$} & $\mathbf{C t}$ & 22.20 & 21.75 & 21.61 & 23.04 & 23.02 \\
\hline & Fold change & $1.00^{\mathrm{c}}$ & $1.70^{\mathrm{a}}$ & $1.47^{\mathrm{b}}$ & $0.55^{\mathrm{d}}$ & $0.57^{\mathrm{d}}$ \\
\hline & $\mathbf{N}$ & 5 & 8 & 5 & 5 & 8 \\
\hline \multirow{3}{*}{$\begin{array}{l}\text { Individual } \\
\text { verification }\end{array}$} & $\mathbf{C t}$ & 30.29 & 32.57 & 31.00 & 29.85 & 35.80 \\
\hline & Fold change & $1.00^{\mathrm{b}}$ & $0.65^{\mathrm{c}}$ & $1.06^{\mathrm{b}}$ & $2.43^{\mathrm{a}}$ & $0.07^{\mathrm{d}}$ \\
\hline & $\mathbf{N}$ & 4 & 4 & 4 & 4 & 4 \\
\hline
\end{tabular}

Results of three analyses of RAMP3 expression in the hypothalamus of animals given 24 hour access to sugar solutions. Rat Obesity RT² Profiler ${ }^{\mathrm{TM}}$ PCR Array (PARN017A, SABiosciences) was used to obtain initial estimates of changes to RAMP3. Pooled verification, followed by individual verification, was then performed using RT-PCR and primers designed in house. Primer sequences for pooled and individual verification assays are found in Table 1. PCR array and pooled verification assays were performed on pooled hypothalamic tissue from all animals in each group. Individual verification was performed on individual hypothalamic tissue from four rats from each group. Averages of the four individual assays are presented. Averages of each measurement that share a common superscript are not different from one another $(\mathrm{p}>0.05)$. 
Table 19. Summary of analyses used to determine the effect of sugar solution access on hypothalamic TNF- $\alpha$.

\begin{tabular}{|l|l|l|l|l|l|l|}
\hline & & Control & Glucose & Sucrose & \multicolumn{1}{|c|}{ HFCS } & Fructose \\
\hline \multirow{4}{*}{ PCR Array } & $\mathbf{C t}$ & 32.76 & 32.40 & 32.30 & 32.96 & 32.55 \\
\cline { 2 - 7 } & Fold change & $1.00^{\mathrm{b}}$ & $1.65^{\mathrm{a}}$ & $1.40^{\mathrm{ab}}$ & $1.06^{\mathrm{b}}$ & $1.26^{\mathrm{ab}}$ \\
\cline { 2 - 7 } & $\mathbf{n}$ & 5 & 8 & 5 & 5 & 8 \\
\hline \multirow{2}{*}{$\begin{array}{l}\text { Pooled } \\
\text { verification }\end{array}$} & $\mathbf{C t}$ & 34.48 & 34.24 & 33.71 & 34.90 & 33.74 \\
\cline { 2 - 7 } & Fold change & $1.00^{\mathrm{b}}$ & $1.48^{\mathrm{a}}$ & $1.67^{\mathrm{a}}$ & $0.74^{\mathrm{b}}$ & $1.67^{\mathrm{a}}$ \\
\cline { 2 - 7 } & $\mathbf{n}$ & 5 & 8 & 5 & 5 & 8 \\
\hline
\end{tabular}

Results of two analyses of TNF- $\alpha$ expression in the hypothalamus of animals given 24 hour access to sugar solutions. Rat Obesity RT ${ }^{2}$ Profiler ${ }^{\mathrm{TM}}$ PCR Array (PARN017A, SABiosciences) was used to obtain initial estimates of changes to TNF- $\alpha$. Pooled verification was then performed using RT-PCR and primers designed in house. Primer sequences for pooled verification assays are found in Table 1. PCR array and pooled verification assays were performed on pooled hypothalamic tissue from all animals in each group. Averages of each measurement that share a common superscript are not different from one another ( $p>0.05)$. 
Table 20. Summary of analyses used to determine the effect of sugar solution access on hypothalamic TRH.

\begin{tabular}{|l|l|l|l|l|l|l|}
\hline \multirow{4}{*}{ PCR Array } & $\mathbf{C t}$ & \multicolumn{1}{|c|}{ Control } & Glucose & Sucrose & \multicolumn{1}{|c|}{ HFCS } & Fructose \\
\cline { 2 - 7 } & Fold change & 25.23 & 26.46 & 25.63 & 26.71 & 25.07 \\
\cline { 2 - 7 } & $\mathbf{n}$ & 5 & $0.55^{\mathrm{d}}$ & $0.77^{\mathrm{c}}$ & $0.43^{\mathrm{d}}$ & $1.22^{\mathrm{a}}$ \\
\hline \multirow{3}{*}{$\begin{array}{l}\text { Pooled } \\
\text { verification }\end{array}$} & $\mathbf{C t}$ & 23.20 & 21.57 & 20.84 & 22.89 & 21.30 \\
\cline { 2 - 7 } & Fold change & $1.00^{\mathrm{c}}$ & $3.86^{\mathrm{b}}$ & $5.04^{\mathrm{a}}$ & $1.22^{\mathrm{c}}$ & $3.72^{\mathrm{b}}$ \\
\cline { 2 - 7 } & $\mathbf{n}$ & 5 & 8 & 5 & 5 & 8 \\
\hline
\end{tabular}

Results of two analyses of TRH expression in the hypothalamus of animals given 24

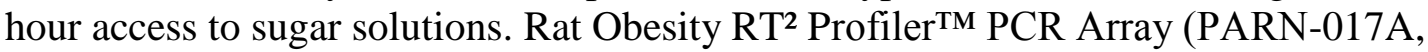
SABiosciences) was used to obtain initial estimates of changes to TRH. Pooled verification was then performed using RT-PCR and primers designed in house. Primer sequences for pooled verification assays are found in Table 1. PCR array and pooled verification assays were performed on pooled hypothalamic tissue from all animals in each group. Averages of each measurement that share a common superscript are not different from one another ( $p>0.05)$. 
Table 21. Summary of analyses used to determine the effect of sugar solution access on hypothalamic UCN.

\begin{tabular}{|l|l|l|l|l|l|l|}
\hline \multirow{4}{*}{ PCR Array } & $\mathbf{C t}$ & \multicolumn{1}{|c|}{ Control } & Glucose & Sucrose & \multicolumn{1}{|c|}{ HFCS } & Fructose \\
\cline { 2 - 7 } & Fold change & $1.00^{\mathrm{b}}$ & 35.50 & 33.34 & 34.74 & 35.78 \\
\cline { 2 - 7 } & $\mathbf{n}$ & 5 & 8 & $4.08^{\mathrm{b}}$ & $1.44^{\mathrm{b}}$ & $1.02^{\mathrm{b}}$ \\
\hline \multirow{2}{*}{$\begin{array}{l}\text { Pooled } \\
\text { verification }\end{array}$} & $\mathbf{C t}$ & 37.01 & 33.99 & 36.95 & 36.48 & 36.45 \\
\cline { 2 - 7 } & $\mathbf{n}$ & 5 & 8 & 5 & 5 & 8 \\
\hline
\end{tabular}

Results of two analyses of UCN expression in the hypothalamus of animals given 24

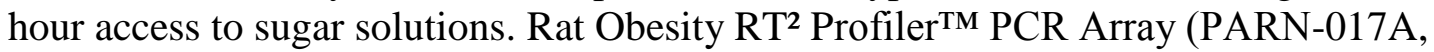
SABiosciences) was used to obtain initial estimates of changes to UCN. Pooled verification was then performed using RT-PCR and primers designed in house. Primer sequences for pooled verification assays are found in Table 1. PCR array and pooled verification assays were performed on pooled hypothalamic tissue from all animals in each group. Fold change is not presented for pooled verification because Ct was greater than 35 and thus not 'significant.' Averages of each measurement that share a common superscript are not different from one another $(\mathrm{p}>0.05)$. 


\section{Appendices}

\section{Appendix A. List of genes on $\mathrm{RT}^{2} \mathrm{PCR}$ array}

\begin{tabular}{|c|c|c|c|c|}
\hline Unigene & GeneBank & Symbol & Description & Gene Name \\
\hline Rn.202559 & NM_016989 & Adcyap1 & $\begin{array}{c}\text { Adenylate cyclase } \\
\text { activating polypeptide } 1\end{array}$ & Pacap \\
\hline Rn.88408 & NM_133511 & Adcyap1r1 & $\begin{array}{c}\text { Adenylate cyclase } \\
\text { activating polypeptide } 1 \\
\text { receptor } 1\end{array}$ & $\begin{array}{c}\text { PACAP- } \\
\text { R1A, } \\
\text { PACAPR1, } \\
\text { PACAPR1A }\end{array}$ \\
\hline Rn.24299 & NM_144744 & Adipoq & $\begin{array}{l}\text { Adiponectin, C1Q and } \\
\text { collagen domain } \\
\text { containing }\end{array}$ & $\begin{array}{l}\text { Acdc, } \\
\text { Acrp30 }\end{array}$ \\
\hline Rn.104556 & NM_207587 & Adipor1 & Adiponectin receptor 1 & - \\
\hline Rn.101984 & NM_001037979 & Adipor2 & Adiponectin receptor 2 & - \\
\hline Rn.10296 & NM_138505 & Adra2b & $\begin{array}{l}\text { Adrenergic, alpha-2B-, } \\
\text { receptor }\end{array}$ & - \\
\hline Rn.87064 & NM_012701 & Adrb1 & $\begin{array}{l}\text { Adrenergic, beta-1-, } \\
\text { receptor }\end{array}$ & $\begin{array}{c}\text { B1AR, } \\
\text { RATB1AR }\end{array}$ \\
\hline Rn.137597 & NM_033650 & Agrp & $\begin{array}{l}\text { Agouti related protein } \\
\text { homolog (mouse) }\end{array}$ & - \\
\hline Rn.15739 & NM_012737 & Apoa4 & Apolipoprotein A-IV & $\begin{array}{l}\text { Apo-AIV, } \\
\text { ApoA-IV, } \\
\text { apoAIV }\end{array}$ \\
\hline Rn.53846 & NM_031351 & Atrn & Attractin & - \\
\hline Rn.11266 & NM_012513 & Bdnf & $\begin{array}{c}\text { Brain-derived } \\
\text { neurotrophic factor }\end{array}$ & MGC105254 \\
\hline Rn.86415 & NM_152845 & Brs3 & Bombesin-like receptor 3 & - \\
\hline Rn.11378 & NM_016994 & $\mathrm{C} 3$ & $\begin{array}{l}\text { Complement component } \\
3\end{array}$ & - \\
\hline Rn.90085 & NM_017338 & Calca & $\begin{array}{l}\text { Calcitonin-related } \\
\text { polypeptide alpha }\end{array}$ & $\begin{array}{c}\text { CAL6, } \\
\text { CGRP, Cal1, } \\
\text { Calc, } \\
\text { RATCAL6, } \\
\text { calcitonin }\end{array}$ \\
\hline Rn.10062 & NM_053816 & Calcr & Calcitonin receptor & - \\
\hline Rn.89164 & NM_017110 & Cartpt & CART prepropeptide & Cart \\
\hline Rn.9781 & NM_012829 & Cck & Cholecystokinin & - \\
\hline Rn.10184 & NM_012688 & Cckar & $\begin{array}{l}\text { Cholecystokinin A } \\
\text { receptor }\end{array}$ & Cck-ar \\
\hline Rn.6714 & NM_013139 & Clps & Colipase, pancreatic & COLQ \\
\hline
\end{tabular}


Appendix A. List of genes on $\mathrm{RT}^{2}$ PCR array (continued)

\begin{tabular}{|c|c|c|c|c|}
\hline Unigene & GeneBank & Symbol & Description & Gene Name \\
\hline Rn.89774 & NM_012784 & Cnr1 & $\begin{array}{c}\text { Cannabinoid receptor } 1 \\
\text { (brain) }\end{array}$ & SKR6R \\
\hline Rn.6067 & NM_013166 & Cntf & $\begin{array}{c}\text { Ciliary neurotrophic } \\
\text { factor }\end{array}$ & - \\
\hline Rn.55036 & NM_001003929 & Cntfr & $\begin{array}{l}\text { Ciliary neurotrophic } \\
\text { factor receptor }\end{array}$ & - \\
\hline Rn.10349 & NM_031019 & $\mathrm{Crh}$ & $\begin{array}{c}\text { Corticotropin releasing } \\
\text { hormone }\end{array}$ & $\mathrm{CRF}$ \\
\hline Rn.10499 & NM_030999 & Crhr1 & $\begin{array}{l}\text { Corticotropin releasing } \\
\text { hormone receptor } 1\end{array}$ & - \\
\hline Rn.24039 & NM_012546 & Drd1a & Dopamine receptor D1A & $\begin{array}{l}\text { D1a, Drd-1, } \\
\text { Drd1 }\end{array}$ \\
\hline Rn.87299 & NM_012547 & Drd2 & Dopamine receptor D2 & - \\
\hline Rn.8929 & NM_033237 & Gal & Galanin prepropeptide & Galn \\
\hline Rn.10213 & NM_012958 & Galr1 & Galanin receptor 1 & Galnr1 \\
\hline $\mathrm{Rn} .54383$ & NM_012707 & Gcg & Glucagon & GLP-1 \\
\hline Rn.11225 & NM_172092 & Gcgr & Glucagon receptor & MGC93090 \\
\hline Rn.146351 & NM_001034848 & Gh1 & Growth hormone 1 & $\begin{array}{c}\text { Gh, } \\
\text { RNGHGP }\end{array}$ \\
\hline Rn.2178 & NM_017094 & Ghr & $\begin{array}{l}\text { Growth hormone } \\
\text { receptor }\end{array}$ & $\begin{array}{c}\text { GHR, BP, } \\
\text { MGC124963, } \\
\text { MGC156665 }\end{array}$ \\
\hline Rn.42103 & NM_021669 & Ghrl & $\begin{array}{l}\text { Ghrelin/obestatin } \\
\text { prepropeptide }\end{array}$ & - \\
\hline Rn.74241 & NM_032075 & Ghsr & $\begin{array}{c}\text { Growth hormone } \\
\text { secretagogue receptor }\end{array}$ & - \\
\hline Rn.11408 & NM_012728 & Glp1r & $\begin{array}{l}\text { Glucagon-like peptide } 1 \\
\text { receptor }\end{array}$ & $\begin{array}{c}\text { Glip, } \\
\text { RATGL1RCP }\end{array}$ \\
\hline Rn.138127 & NM_139193 & Prlhr & $\begin{array}{l}\text { Prolactin releasing } \\
\text { hormone receptor }\end{array}$ & Gpr10, Uhr-1 \\
\hline Rn.10822 & NM_031758 & Mchr1 & $\begin{array}{l}\text { Melanin-concentrating } \\
\text { hormone receptor } 1\end{array}$ & $\begin{array}{l}\text { Gpr24, Mch- } \\
\text { 1r, Slc1 }\end{array}$ \\
\hline Rn.10930 & NM_133570 & Grp & Gastrin releasing peptide & - \\
\hline Rn.10316 & NM_012706 & Grpr & $\begin{array}{l}\text { Gastrin releasing peptide } \\
\text { receptor }\end{array}$ & - \\
\hline Rn.7628 & NM_013179 & HcRt & Hypocretin & orexin-A \\
\hline Rn.88262 & NM_013064 & Hcrtr1 & $\begin{array}{l}\text { Hypocretin (orexin) } \\
\text { receptor } 1\end{array}$ & Hctr1 \\
\hline
\end{tabular}




\section{Appendix A. List of genes on $\mathrm{RT}^{2} \mathrm{PCR}$ array (continued)}

\begin{tabular}{|c|c|c|c|c|}
\hline Unigene & GeneBank & Symbol & Description & Gene Name \\
\hline Rn.81032 & NM_017018 & Hrh1 & Histamine receptor $\mathrm{H} 1$ & Hisr \\
\hline Rn.9935 & NM_012765 & Htr2c & $\begin{array}{l}\text { 5-hydroxytryptamine } \\
\text { (serotonin) receptor } 2 \mathrm{C}\end{array}$ & $\begin{array}{c}\text { 5-HT2C, 5- } \\
\text { HTR2C, 5HT- } \\
\text { 1C }\end{array}$ \\
\hline Rn.11394 & NM_012586 & Iapp & Islet amyloid polypeptide & - \\
\hline Rn.12300 & NM_017019 & Il1a & Interleukin 1 alpha & IL-1 alpha \\
\hline Rn.9869 & NM_031512 & Il1b & Interleukin 1 beta & - \\
\hline Rn.9758 & NM_013123 & Il1r1 & $\begin{array}{c}\text { Interleukin } 1 \text { receptor, } \\
\text { type I }\end{array}$ & - \\
\hline Rn.9873 & NM_012589 & Il6 & Interleukin 6 & ILg6, Ifnb2 \\
\hline Rn.1716 & NM_017020 & Il6r & Interleukin 6 receptor & IL6R1, Il6ra \\
\hline Rn.962 & NM_019129 & Ins1 & Insulin 1 & - \\
\hline Rn.989 & NM_019130 & Ins2 & Insulin 2 & - \\
\hline Rn.9876 & NM_017071 & Insr & Insulin receptor & - \\
\hline Rn.44444 & NM_013076 & Lep & Leptin & OB, obese \\
\hline Rn.9891 & NM_012596 & Lepr & Leptin receptor & $\mathrm{Fa}$ \\
\hline Rn.215838 & NM_001025270 & $\mathrm{Mc} 3 \mathrm{r}$ & Melanocortin 3 receptor & - \\
\hline Rn.130371 & XM_218815 & $\mathrm{Nmb}$ & Neuromedin B & RGD1562710 \\
\hline Rn.89709 & NM_012799 & Nmbr & Neuromedin B receptor & NMB-R \\
\hline Rn.47720 & NM_022239 & $\mathrm{Nmu}$ & Neuromedin U & - \\
\hline Rn.54457 & NM_023100 & Nmur1 & Neuromedin U receptor 1 & Gpr66 \\
\hline Rn.9714 & NM_012614 & Npy & Neuropeptide Y & $\begin{array}{c}\text { NPY02, } \\
\text { RATNPY, } \\
\text { RATNPY02 }\end{array}$ \\
\hline Rn.11642 & NM_001113357 & Npy1r & $\begin{array}{c}\text { Neuropeptide Y receptor } \\
\text { Y1 }\end{array}$ & $\begin{array}{c}\text { MGC109393, } \\
\text { NPY-1 }\end{array}$ \\
\hline Rn.90070 & NM_012576 & $\mathrm{Nr} 3 \mathrm{c} 1$ & $\begin{array}{c}\text { Nuclear receptor } \\
\text { subfamily } 3 \text {, group C, } \\
\text { member } 1\end{array}$ & GR, Gcr, Grl \\
\hline Rn.39098 & NM_021589 & Ntrk1 & $\begin{array}{l}\text { Neurotrophic tyrosine } \\
\text { kinase, receptor, type } 1\end{array}$ & Trk \\
\hline Rn.60814 & NM_001102381 & Nts & Neurotensin & - \\
\hline Rn.200149 & NM_001108967 & Ntsr1 & Neurotensin receptor 1 & Ntsr \\
\hline Rn.89571 & NM_017167 & Oprk1 & Opioid receptor, kappa 1 & - \\
\hline
\end{tabular}


Appendix A. List of genes on $\mathrm{RT}^{2}$ PCR array (continued)

\begin{tabular}{|c|c|c|c|c|}
\hline Unigene & GeneBank & Symbol & Description & Gene Name \\
\hline Rn.10118 & NM_013071 & Oprm1 & Opioid receptor, mu 1 & $\begin{array}{l}\text { MORA, } \\
\text { Oprm, } \\
\text { Oprrm1 }\end{array}$ \\
\hline Rn.1129 & NM_030996 & Sigmar1 & $\begin{array}{c}\text { Sigma non-opioid } \\
\text { intracellular receptor } 1\end{array}$ & Oprs1 \\
\hline Rn.108195 & NM_139326 & Pomc & Proopiomelanocortin & $\begin{array}{l}\text { Pomc1, } \\
\text { Pomc2 }\end{array}$ \\
\hline Rn.9753 & NM_013196 & Ppara & $\begin{array}{l}\text { Peroxisome proliferator } \\
\text { activated receptor alpha }\end{array}$ & PPAR \\
\hline Rn.23443 & NM_013124 & Pparg & $\begin{array}{l}\text { Peroxisome proliferator- } \\
\text { activated receptor gamma }\end{array}$ & - \\
\hline Rn.19172 & NM_031347 & Ppargcla & $\begin{array}{c}\text { Peroxisome proliferator- } \\
\text { activated receptor } \\
\text { gamma, coactivator } 1 \\
\text { alpha }\end{array}$ & Ppargc1 \\
\hline Rn.11317 & NM_012637 & Ptpn1 & $\begin{array}{c}\text { Protein tyrosine } \\
\text { phosphatase, non-receptor } \\
\text { type } 1\end{array}$ & $\begin{array}{l}\text { MGC93562, } \\
\text { Ptp }\end{array}$ \\
\hline Rn.13173 & NM_001034080 & Pyy & Peptide YY (mapped) & $\begin{array}{c}\text { GHYY, } \\
\text { RATGHYY, } \\
\text { Yy, peptide- } \\
\text { YY }\end{array}$ \\
\hline $\mathrm{Rn} .48672$ & NM_020100 & Ramp3 & $\begin{array}{l}\text { Receptor (G protein- } \\
\text { coupled) activity } \\
\text { modifying protein } 3\end{array}$ & - \\
\hline Rn.11286 & NM_031767 & Sort1 & Sortilin 1 & $\mathrm{Nt3}, \mathrm{Nts} 3$ \\
\hline Rn.34418 & NM_012659 & Sst & Somatostatin & $\begin{array}{l}\text { SS-14, SS- } \\
28, \text { Smst }\end{array}$ \\
\hline $\mathrm{Rn} .42915$ & NM_012719 & Sstr1 & Somatostatin receptor 1 & Gpcrrna \\
\hline Rn.88692 & NM_012672 & Thrb & $\begin{array}{l}\text { Thyroid hormone } \\
\text { receptor beta }\end{array}$ & $\begin{array}{c}\text { C-erba-beta, } \\
\text { ERBA2, } \\
\text { Nr1a2, } \\
\text { RATT3REC, } \\
\text { T3rec, } \\
\text { TRbeta }\end{array}$ \\
\hline Rn.2275 & NM_012675 & Tnf & $\begin{array}{l}\text { Tumor necrosis factor } \\
\text { (TNF superfamily, } \\
\text { member } 2 \text { ) }\end{array}$ & $\begin{array}{c}\text { MGC124630, } \\
\text { RATTNF, } \\
\text { TNF-alpha, } \\
\text { Tnfa }\end{array}$ \\
\hline
\end{tabular}


Appendix A. List of genes on $\mathrm{RT}^{2}$ PCR array (continued)

\begin{tabular}{|c|c|c|c|c|}
\hline Unigene & GeneBank & Symbol & Description & Gene Name \\
\hline Rn.22 & NM_013046 & Trh & $\begin{array}{c}\text { Thyrotropin releasing } \\
\text { hormone }\end{array}$ & THR, TRH01 \\
\hline Rn.9962 & NM_013047 & Trhr & $\begin{array}{l}\text { Thyrotropin releasing } \\
\text { hormone receptor }\end{array}$ & - \\
\hline Rn.10190 & NM_019150 & Ucn & Urocortin & - \\
\hline Rn.10281 & NM_012682 & Ucp1 & $\begin{array}{c}\text { Uncoupling protein } 1 \\
\text { (mitochondrial, proton } \\
\text { carrier) }\end{array}$ & $\begin{array}{l}\text { MGC108736, } \\
\text { Ucp, Ucpa, } \\
\text { Uncp }\end{array}$ \\
\hline Rn.973 & NM_001007604 & Rplp1 & $\begin{array}{c}\text { Ribosomal protein, large, } \\
\text { P1 }\end{array}$ & MGC72935 \\
\hline Rn.47 & NM_012583 & Hprt1 & $\begin{array}{c}\text { Hypoxanthine } \\
\text { phosphoribosyltransferase } \\
1\end{array}$ & $\begin{array}{c}\text { Hgprtase, } \\
\text { Hprt, } \\
\text { MGC112554 }\end{array}$ \\
\hline Rn.92211 & NM_173340 & Rpl13a & Ribosomal protein L13A & - \\
\hline Rn.107896 & NM_017025 & Ldha & Lactate dehydrogenase $\mathrm{A}$ & Ldh1 \\
\hline Rn.94978 & NM_031144 & Actb & Actin, beta & Actx \\
\hline N/A & U26919 & RGDC & $\begin{array}{l}\text { Rat Genomic DNA } \\
\text { Contamination }\end{array}$ & RGDC \\
\hline N/A & SA_00104 & RTC & $\begin{array}{c}\text { Reverse Transcription } \\
\text { Control }\end{array}$ & RTC \\
\hline N/A & SA_00104 & RTC & $\begin{array}{c}\text { Reverse Transcription } \\
\text { Control }\end{array}$ & RTC \\
\hline $\mathrm{N} / \mathrm{A}$ & SA_00104 & RTC & $\begin{array}{c}\text { Reverse Transcription } \\
\text { Control }\end{array}$ & RTC \\
\hline N/A & SA_00103 & PPC & Positive PCR Control & PPC \\
\hline N/A & SA_00103 & PPC & Positive PCR Control & PPC \\
\hline N/A & SA_00103 & PPC & Positive PCR Control & PPC \\
\hline
\end{tabular}

List of genes on $\mathrm{RT}^{2}$ PCR array (SABioscience, PARN-017A). Utilizing RT-PCR analysis, each array profiles the expression of 84 genes related to obesity, including genes that code for orexigenic peptides, hormones, and receptors, anorectic peptides, hormones, and receptors, and central and peripheral signaling molecules related to energy expenditure. Array also includes 5 housekeepers and 7 controls. 
Appendix B. Results of $\mathrm{RT}^{2} \mathrm{PCR}$ array

\begin{tabular}{|l|r|r|r|r|}
\hline \multicolumn{5}{|c|}{ Fold Change (comparing to control group) } \\
\hline Symbol & Fructose & Glucose & \multicolumn{1}{c|}{ HFCS } & \multicolumn{1}{c|}{ Sucrose } \\
\hline Adcyap1 & 1.0182 & 1.0345 & 1.0852 & 1 \\
\hline Adcyap1r1 & 0.7479 & 0.7366 & 0.6704 & 0.7873 \\
\hline Adipoq & 2.3311 & 3.5406 & 1.3315 & 1.014 \\
\hline Adipor1 & 0.97 & 1.1439 & 0.9781 & 0.9727 \\
\hline Adipor2 & 0.9801 & 1.0526 & 0.8111 & 0.9428 \\
\hline Adra2b & 0.48 & 1.1559 & 0.347 & 0.8586 \\
\hline Adrb1 & 1.0324 & 1.1599 & 1.2167 & 0.8322 \\
\hline Agrp & 1.0541 & 1.2649 & 1.9834 & 0.9593 \\
\hline Apoa4 & 0.5767 & 0.8639 & 1.1511 & 0.2784 \\
\hline Atrn & 0.97 & 0.9069 & 0.8055 & 0.8526 \\
\hline Bdnf & 1.0468 & 1.2388 & 1.2861 & 1.0497 \\
\hline Brs3 & 1.0989 & 0.9356 & 1.0056 & 1.0905 \\
\hline C3 & 0.9019 & 1.2218 & 0.9679 & 1.2702 \\
\hline Calca & 0.8712 & 0.76 & 0.694 & 1.1134 \\
\hline Calcr & 1.1736 & 0.76 & 1.0777 & 1.1408 \\
\hline Cartpt & 0.8213 & 0.9389 & 1.1157 & 1.0497 \\
\hline Cck & 0.6289 & 1.9779 & 1.3928 & 1.2269 \\
\hline Cckar & 1.1736 & 0.7366 & 0.8111 & 0.8766 \\
\hline Clps & 0.9767 & 1.5572 & 1.5616 & 1.4794 \\
\hline Cnr1 & 1.1181 & 0.8061 & 1.2596 & 0.917 \\
\hline Cntf & 0.9835 & 1.0063 & 0.8456 & 0.9526 \\
\hline Cntfr & 1.0578 & 1.0203 & 0.8876 & 0.9044 \\
\hline Crh & 1.2066 & 0.873 & 0.484 & 0.7552 \\
\hline Crhr1 & 1.0253 & 1.0417 & 0.9221 & 0.8265 \\
\hline Drd1a & 1.0837 & 0.8259 & 2.0677 & 0.6974 \\
\hline Drd2 & 1.2449 & 1.3186 & 1.4671 & 0.9862 \\
\hline Gal & 1.08 & 0.8202 & 1.1794 & 1.0353 \\
\hline Galr1 & 1.08 & 0.7895 & 0.8397 & 0.9593 \\
\hline Gcg & 1.0875 & 1.287 & 1.2 & 1.3708 \\
\hline Gcgr & 1.1736 & 0.9324 & 0.935 & 0.9862 \\
\hline Gh1 & 1.0875 & 3.2693 & 1.2 & 1.014 \\
\hline Ghr & 1.0725 & 0.852 & 1.0231 & 1.0353 \\
\hline Ghrl & 1.0147 & 0.9292 & 0.7361 & 0.8351 \\
\hline Ghsr & 1.2492 & 0.855 & 1.0126 & 0.8858 \\
\hline Glp1r & 1.0762 & 0.9069 & 1.1551 & 0.8675 \\
\hline Prlhr & 0.95 & 0.6547 & 0.5657 & 0.9395 \\
\hline Mchr1 & 1.0007 & 0.9356 & 0.9382 & 0.933 \\
\hline Grp & 1.1258 & 0.8882 & 1.0852 & 1.1647 \\
\hline & & & & \\
& & & & \\
\hline
\end{tabular}


Appendix B. Results of RT ${ }^{2}$ PCR array (continued)

\begin{tabular}{|l|r|r|r|r|}
\hline \multirow{2}{*}{ Symbol } & \multicolumn{5}{|c|}{ Fold Change (comparing to control group) } \\
\hline Grpr & 1.19 & 0.8699 & 0.8693 & \multicolumn{1}{c|}{ Sucrose } \\
\hline HcRt & 0.6139 & 0.7392 & 1.1392 & 0.1212 \\
\hline Hcrtr1 & 1.0725 & 0.8287 & 0.7889 & 0.9013 \\
\hline Hrh1 & 1.0147 & 0.8033 & 0.7972 & 0.8467 \\
\hline Htr2c & 1.1142 & 0.9356 & 0.8111 & 1.014 \\
\hline Iapp & 2.2831 & 1.9986 & 1.2 & 1.1096 \\
\hline Il1a & 1.0147 & 1.1925 & 0.9546 & 1.7471 \\
\hline Il1b & 1.2932 & 0.9487 & 0.8426 & 1.1975 \\
\hline Il1r1 & 1.1655 & 1.0563 & 0.9781 & 1.0317 \\
\hline Il6 & 0.9176 & 1.1243 & 0.8282 & 1.5105 \\
\hline Il6ra & 1.2277 & 1.1802 & 1.2083 & 1.3472 \\
\hline Ins1 & 0.9938 & 1.0973 & 0.7621 & 0.9363 \\
\hline Ins2 & 0.7989 & 0.6616 & 0.4707 & 0.9727 \\
\hline Insr & 0.9767 & 0.8005 & 0.8938 & 0.9202 \\
\hline Lep & 1.0875 & 1.287 & 1.2 & 1.014 \\
\hline Lepr & 0.7906 & 1.2959 & 0.9849 & 1.0981 \\
\hline Mc3r & 1.0762 & 0.8944 & 1.0629 & 0.9559 \\
\hline Nmb_predicted & 1.08 & 1.0168 & 1.0592 & 0.9593 \\
\hline Nmbr & 0.7797 & 1.06 & 0.6988 & 0.8858 \\
\hline Nmu & 1.0837 & 1.105 & 1.3041 & 0.3776 \\
\hline Nmur1 & 1.0989 & 1.0822 & 1.0852 & 1.0461 \\
\hline NPY & 1.0112 & 1.1321 & 2.2705 & 1.0317 \\
\hline NPY1r & 0.9801 & 0.9653 & 0.831 & 1.1057 \\
\hline Nr3c1 & 0.905 & 0.9389 & 0.8139 & 0.9559 \\
\hline Ntrk1 & 1.8545 & 1.1966 & 1.2041 & 0.9428 \\
\hline Nts & 1.2932 & 0.9586 & 1.1511 & 1.244 \\
\hline Ntsr1 & 1.0951 & 1.4379 & 0.9382 & 1.0943 \\
\hline Oprk1 & 0.9633 & 0.76 & 0.8282 & 0.9298 \\
\hline Oprm1 & 0.8386 & 0.989 & 0.5795 & 0.9931 \\
\hline Opr1 & 1.1455 & 0.952 & 0.9 & 0.9526 \\
\hline Pomc & 1.0837 & 0.8639 & 1.1471 & 0.8066 \\
\hline Ppara & 1.1416 & 1.0822 & 0.7889 & 1.0681 \\
\hline Pparg & 1.0504 & 1.3604 & 0.726 & 1.1567 \\
\hline Ppargc1a & 0.9733 & 1.0098 & 0.9 & 0.895 \\
\hline Ptpn1 & 1.0762 & 1.0238 & 1.0446 & 1.0681 \\
\hline Pyy & 1.0182 & 0.5963 & 0.632 & 1.0461 \\
\hline Ramp3 & 0.5216 & 1.3186 & 0.4407 & 1.0943 \\
\hline Sort1 & 1.0288 & 1.0747 & 1.089 & 1.007 \\
\hline & & & & \\
\hline
\end{tabular}


Appendix B. Results of $\mathrm{RT}^{2}$ PCR array (continued)

\begin{tabular}{|l|r|r|r|r|}
\hline \multirow{2}{*}{ Symbol } & \multicolumn{4}{|c|}{ Fold Change (comparing to control group) } \\
\hline Sst & Fructose & \multicolumn{1}{c|}{ Glucose } & \multicolumn{1}{c|}{ HFCS } & \multicolumn{1}{c|}{ Sucrose } \\
\hline Sstr1 & 1.1181 & 0.8287 & 0.831 & 1.0035 \\
\hline Thrb & 1.1219 & 0.8316 & 1.0303 & 0.8039 \\
\hline Tnf & 1.0147 & 0.7732 & 1.1672 & 0.8123 \\
\hline Trh & 1.2535 & 1.646 & 1.041 & 1.3899 \\
\hline Trhr & 1.2193 & 0.5506 & 0.4302 & 0.7711 \\
\hline Ucn & 1.0913 & 1.105 & 0.9849 & 0.9931 \\
\hline Ucp1 & 1.0875 & 4.0812 & 1.4369 & 1.014 \\
\hline Rplp1 & 0.9633 & 0.784 & 0.8633 & 0.8438 \\
\hline Hprt1 & 0.9801 & 0.9993 & 0.9986 & 0.9965 \\
\hline Rpl13a & 0.9369 & 1.0028 & 1.1119 & 1.0389 \\
\hline Ldha & 1.0651 & 0.9686 & 0.9063 & 1.0792 \\
\hline Actb & 0.9337 & 1.0133 & 1.0021 & 0.8766 \\
\hline RGDC & 1.0951 & 1.0168 & 0.9917 & 1.021 \\
\hline RTC & 1.0875 & 1.287 & 1.2 & 1.014 \\
\hline RTC & 0.9467 & 0.8491 & 0.9917 & 0.9862 \\
\hline RTC & 0.9938 & 0.8852 & 1.0056 & 0.9965 \\
\hline PPC & 1.0504 & 0.876 & 1.0629 & 1.0389 \\
\hline PPC & 1.0432 & 1.2825 & 1.2816 & 1.057 \\
\hline PPC & 1.2406 & 1.3232 & 1.35 & 1.0497 \\
\hline & 1.1818 & 1.305 & 1.2466 & 1.0943 \\
\hline
\end{tabular}

Complete results of findings from $\mathrm{RT}^{2}$ PCR array (SABioscience, PARN-017A). Presented is the average fold change from two replicate experiments. PCR array was performed on pooled hypothalamic tissue from all animals in each group. Fold change was obtained from manufactures online analysis tool and calculated as $2^{\wedge}(-$ $\mathrm{ddCt}$ ). 


\section{Literature Cited}

1. Jia H, Lubetkin EI. Trends in quality-adjusted life-years lost contributed by smoking and obesity. Am J Prev Med. 2010;38:138-44.

2. Flegal KM, Carroll MD, Ogden CL, Curtin LR. Prevalence and trends in obesity among US adults, 1999-2008. JAMA. 2010;303:235-41.

3. Canoy D, Buchan I. Challenges in obesity epidemiology. Obes Rev. 2007;8 Suppl 1:1-11.

4. Paeratakul S, York-Crowe EE, Williamson DA, Ryan DH, Bray GA. Americans on diet: results from the 1994-1996 Continuing Survey of Food Intakes by Individuals. J Am Diet Assoc. 2002;102:1247-51.

5. Johnson RJ, Segal MS, Sautin Y, Nakagawa T, Feig DI, Kang DH, Gersch MS, Benner S, Sanchez-Lozada LG. Potential role of sugar (fructose) in the epidemic of hypertension, obesity and the metabolic syndrome, diabetes, kidney disease, and cardiovascular disease. Am J Clin Nutr. 2007;86:899-906.

6. van Dam RM, Seidell JC. Carbohydrate intake and obesity. Eur J Clin Nutr. 2007;61 Suppl 1:S75-99.

7. Bray GA, Paeratakul S, Popkin BM. Dietary fat and obesity: a review of animal, clinical and epidemiological studies. Physiol Behav. 2004;83:549-55.

8. Malik VS, Popkin BM, Bray GA, Despres JP, Hu FB. Sugar-sweetened beverages, obesity, type 2 diabetes mellitus, and cardiovascular disease risk. Circulation. 2010;121:1356-64.

9. Bocarsly ME, Powell ES, Avena NM, Hoebel BG. High-fructose corn syrup causes characteristics of obesity in rats: increased body weight, body fat and triglyceride levels. Pharmacol Biochem Behav. 2010;97:101-6.

10. Melanson KJ, Angelopoulos TJ, Nguyen V, Zukley L, Lowndes J, Rippe JM. High-fructose corn syrup, energy intake, and appetite regulation. Am J Clin Nutr. 2008;88:1738S-44S.

11. Soenen S, Westerterp-Plantenga MS. No differences in satiety or energy intake after high-fructose corn syrup, sucrose, or milk preloads. Am J Clin Nutr. 2007;86:1586-94.

12. Dhillo WS. Appetite regulation: an overview. Thyroid. 2007 May;17:433-45.

13. Woods SC, D'Alessio DA. Central control of body weight and appetite. J Clin Endocrinol Metab. 2008;93:S37-50. 
14. Hetherington AW, Ranson SW. Hypothalamic lesions and adiposity in the rat. The Anatomical Record. 1940;78:149-72.

15. Lutz TA. The role of amylin in the control of energy homeostasis. Am J Physiol Regul Integr Comp Physiol. 2010;298:R1475-84.

16. Young A. Amylin and the integrated control of nutrient influx. Adv Pharmacol. 2005;52:67-77.

17. Lutz TA. Steve Woods's contribution to research on amylin's eating inhibitory effect. Physiol Behav. 2011;103:25-30.

18. Dobolyi A. Central amylin expression and its induction in rat dams. J Neurochem. 2009;111:1490-500.

19. Konner AC, Janoschek R, Plum L, Jordan SD, Rother E, Ma X, Xu C, Enriori $\mathrm{P}$, Hampel B, et al. Insulin action in AgRP-expressing neurons is required for suppression of hepatic glucose production. Cell Metab. 2007;5:438-49.

20. Gaysinskaya VA, Karatayev O, Shuluk J, Leibowitz SF. Hyperphagia induced by sucrose: relation to circulating and CSF glucose and corticosterone and orexigenic peptides in the arcuate nucleus. Pharmacol Biochem Behav. 2011;97:521-30.

21. Leibowitz SF, Wortley KE. Hypothalamic control of energy balance: different peptides, different functions. Peptides. 2004;25:473-504.

22. Liddle RA. On the Measurement of Cholecystokinin. 1998 1998-05-01.

23. Lo CM, Zhang DM, Pearson K, Ma L, Sun W, Sakai RR, Davidson WS, Liu M, Raybould HE, et al. Interaction of apolipoprotein AIV with cholecystokinin on the control of food intake. Am J Physiol Regul Integr Comp Physiol. 2007;293:R1490-4.

24. Lee SY, Soltesz I. Cholecystokinin: a multi-functional molecular switch of neuronal circuits. Dev Neurobiol. 2011 Jan 1;71:83-91.

25. Cain BM, Connolly K, Blum A, Vishnuvardhan D, Marchand JE, Beinfeld MC. Distribution and colocalization of cholecystokinin with the prohormone convertase enzymes PC1, PC2, and PC5 in rat brain. J Comp Neurol. 2003 Dec $15 ; 467: 307-25$.

26. Cano V, Merino B, Ezquerra L, Somoza B, Ruiz-Gayo M. A cholecystokinin1 receptor agonist (CCK-8) mediates increased permeability of brain barriers to leptin. Br J Pharmacol. 2008;154:1009-15.

27. Lo CM, Obici S, Dong HH, Haas M, Lou D, Kim DH, Liu M, D'Alessio D, Woods SC, Tso P. Impaired insulin secretion and enhanced insulin sensitivity in cholecystokinin-deficient mice. Diabetes. 2011;60:2000-7. 
28. Hisadome K, Reimann F, Gribble FM, Trapp S. CCK stimulation of GLP-1 neurons involves alpha1-adrenoceptor-mediated increase in glutamatergic synaptic inputs. Diabetes. 2011;60:2701-9.

29. Vale W, Spiess J, Rivier C, Rivier J. Characterization of a 41-residue ovine hypothalamic peptide that stimulates secretion of corticotropin and beta-endorphin. Science. 1981 Sep 18;213:1394-7.

30. Sawchenko PE. Evidence for differential regulation of corticotropin-releasing factor and vasopressin immunoreactivities in parvocellular neurosecretory and autonomic-related projections of the paraventricular nucleus. Brain Res. 1987;437:253-63.

31. Widmaier EP, Plotsky PM, Sutton SW, Vale WW. Regulation of corticotropin-releasing factor secretion in vitro by glucose. Am J Physiol. 1988 Sep;255:E287-92.

32. Jang M, Mistry A, Swick AG, Romsos DR. Leptin rapidly inhibits hypothalamic neuropeptide Y secretion and stimulates corticotropin-releasing hormone secretion in adrenalectomized mice. J Nutr. 2000 Nov;130:2813-20.

33. Ulrich-Lai YM, Ostrander MM, Thomas IM, Packard BA, Furay AR, Dolgas CM, Van Hooren DC, Figueiredo HF, Mueller NK, et al. Daily limited access to sweetened drink attenuates hypothalamic-pituitary-adrenocortical axis stress responses. Endocrinology. 2007;148:1823-34.

34. Laugero KD, Gomez F, Manalo S, Dallman MF. Corticosterone infused intracerebroventricularly inhibits energy storage and stimulates the hypothalamopituitary axis in adrenalectomized rats drinking sucrose. Endocrinology. 2002 Dec;143:4552-62.

35. Stice E, Figlewicz DP, Gosnell BA, Levine AS, Pratt WE. The contribution of brain reward circuits to the obesity epidemic. Neurosci Biobehav Rev. 2012 Dec 10.

36. Avena NM, Bocarsly ME, Rada P, Kim A, Hoebel BG. After daily bingeing on a sucrose solution, food deprivation induces anxiety and accumbens dopamine/acetylcholine imbalance. Physiol Behav. 2008;94:309-15.

37. Simansky KJ, Bourbonais KA, Smith GP. Food-related stimuli increase the ratio of 3,4-dihydroxyphenylacetic acid to dopamine in the hypothalamus. Pharmacol Biochem Behav. 1985 Aug;23:253-8.

38. Smith GP, Bourbonais KA, Jerome C, Simansky KJ. Sham feeding of sucrose increases the ratio of 3,4-dihydroxyphenylacetic acid to dopamine in the hypothalamus. Pharmacol Biochem Behav. 1987;26:585-91. 
39. Weatherford SC, Greenberg D, Gibbs J, Smith GP. The potency of D-1 and D-2 receptor antagonists is inversely related to the reward value of sham-fed corn oil and sucrose in rats. Pharmacol Biochem Behav. 1990;37:317-23.

40. Baker RM, Shah MJ, Sclafani A, Bodnar RJ. Dopamine D1 and D2 antagonists reduce the acquisition and expression of flavor-preferences conditioned by fructose in rats. Pharmacol Biochem Behav. 2003;75:55-65.

41. Volkow ND, Wang GJ, Tomasi D, Baler RD. Obesity and addiction: neurobiological overlaps. Obes Rev. 2013 Jan;14:2-18.

42. Azzara AV, Bodnar RJ, Delamater AR, Sclafani A. D1 but not D2 dopamine receptor antagonism blocks the acquisition of a flavor preference conditioned by intragastric carbohydrate infusions. Pharmacol Biochem Behav. 2001;68:709-20.

43. Pritchett CE, Hajnal A. Obesogenic diets may differentially alter dopamine control of sucrose and fructose intake in rats. Physiol Behav. 2011;104:111-6.

44. Yu WZ, Silva RM, Sclafani A, Delamater AR, Bodnar RJ. Role of D(1) and $\mathrm{D}$ (2) dopamine receptors in the acquisition and expression of flavor-preference conditioning in sham-feeding rats. Pharmacol Biochem Behav. 2000;67:537-44.

45. Dym CT, Pinhas A, Robak M, Sclafani A, Bodnar RJ. Genetic variance contributes to dopamine receptor antagonist-induced inhibition of sucrose intake in inbred and outbred mouse strains. Brain Res. 2009;1257:40-52.

46. Norgren R, Hajnal A, Mungarndee SS. Gustatory reward and the nucleus accumbens. Physiol Behav. 2006;89:531-5.

47. Lim CT, Kola B, Korbonits M. The ghrelin/GOAT/GHS-R system and energy metabolism. Rev Endocr Metab Disord. 2011 Sep;12:173-86.

48. Wren AM, Small CJ, Ward HL, Murphy KG, Dakin CL, Taheri S, Kennedy AR, Roberts GH, Morgan DG, et al. The novel hypothalamic peptide ghrelin stimulates food intake and growth hormone secretion. Endocrinology. 2000 Nov;141:4325-8.

49. Sakharova AA, Horowitz JF, Surya S, Goldenberg N, Harber MP, Symons K, Barkan A. Role of growth hormone in regulating lipolysis, proteolysis, and hepatic glucose production during fasting. J Clin Endocrinol Metab. 2008;93:2755-9.

50. Gahete MD, Cordoba-Chacon J, Luque RM, Kineman RD. The rise in growth hormone during starvation does not serve to maintain glucose levels or lean mass but is required for appropriate adipose tissue response in female mice. Endocrinology. 2013;154:263-9.

51. Strauch G, Pandes P, Bricaire H. Fructose induced growth hormone release. J Clin Endocrinol Metab. 1971 Apr;32:582-4. 
52. Hanson ES, Dallman MF. Neuropeptide Y (NPY) may integrate responses of hypothalamic feeding systems and the hypothalamo-pituitary-adrenal axis. J Neuroendocrinol. 1995 Apr;7:273-9.

53. Porte D, Jr., Baskin DG, Schwartz MW. Leptin and insulin action in the central nervous system. Nutr Rev. 2002 Oct;60:S20-9; discussion S68-84, 5-7.

54. van den Top M, Lee K, Whyment AD, Blanks AM, Spanswick D. Orexigensensitive NPY/AgRP pacemaker neurons in the hypothalamic arcuate nucleus. Nat Neurosci. 2004;7:493-4.

55. Schwartz MW, Woods SC, Seeley RJ, Barsh GS, Baskin DG, Leibel RL. Is the energy homeostasis system inherently biased toward weight gain? Diabetes. 2003 Feb;52:232-8.

56. Schwartz MW, Seeley RJ, Woods SC, Weigle DS, Campfield LA, Burn P, Baskin DG. Leptin increases hypothalamic pro-opiomelanocortin mRNA expression in the rostral arcuate nucleus. Diabetes. 1997 Dec;46:2119-23.

57. Rowland NE. Peripheral and central satiety factors in neuropeptide Y-induced feeding in rats. Peptides. 1988;9:989-92.

58. Bailey RJ, Bradley JW, Poyner DR, Rathbone DL, Hay DL. Functional characterization of two human receptor activity-modifying protein 3 variants. Peptides. 2010;31:579-84.

59. Dackor R, Fritz-Six K, Smithies O, Caron K. Receptor activity-modifying proteins 2 and 3 have distinct physiological functions from embryogenesis to old age. J Biol Chem. 2007;282:18094-9.

60. Ventre J, Doebber T, Wu M, MacNaul K, Stevens K, Pasparakis M, Kollias G, Moller DE. Targeted disruption of the tumor necrosis factor-alpha gene: metabolic consequences in obese and nonobese mice. Diabetes. 1997 Sep;46:1526-31.

61. Huypens P. Leptin controls adiponectin production via the hypothalamus. Med Hypotheses. 2007;68:87-90.

62. Wang X, Ge A, Cheng M, Guo F, Zhao M, Zhou X, Liu L, Yang N. Increased hypothalamic inflammation associated with the susceptibility to obesity in rats exposed to high-fat diet. Exp Diabetes Res. 2012;2012:847246.

63. Zhang $\mathrm{X}$, van den Pol AN. Thyrotropin-releasing hormone (TRH) inhibits melanin-concentrating hormone neurons: implications for TRH-mediated anorexic and arousal actions. J Neurosci. 2012;32:3032-43. 
64. Rossi M, Beak SA, Choi SJ, Small CJ, Morgan DG, Ghatei MA, Smith DM, Bloom SR. Investigation of the feeding effects of melanin concentrating hormone on food intake--action independent of galanin and the melanocortin receptors. Brain Res. 1999;846:164-70.

65. Nillni EA, Vaslet C, Harris M, Hollenberg A, Bjorbak C, Flier JS. Leptin regulates prothyrotropin-releasing hormone biosynthesis. Evidence for direct and indirect pathways. J Biol Chem. 2000;275:36124-33.

66. Legradi G, Lechan RM. The arcuate nucleus is the major source for neuropeptide Y-innervation of thyrotropin-releasing hormone neurons in the hypothalamic paraventricular nucleus. Endocrinology. 1998 Jul;139:3262-70.

67. Erlanson-Albertsson C, Lindqvist A. Fructose affects enzymes involved in the synthesis and degradation of hypothalamic endocannabinoids. Regul Pept. 2010;161:87-91.

68. Avena NM, Rada P, Hoebel BG. Underweight rats have enhanced dopamine release and blunted acetylcholine response in the nucleus accumbens while bingeing on sucrose. Neuroscience. 2008;156:865-71.

69. Rada P, Avena NM, Hoebel BG. Daily bingeing on sugar repeatedly releases dopamine in the accumbens shell. Neuroscience. 2005;134:737-44.

70. London E, Lala G, Berger R, Panzenbeck A, Kohli AA, Renner M, Jackson A, Raynor T, Loya K, Castonguay TW. Sucrose access differentially modifies 11 betahydroxysteroid dehydrogenase-1 and hexose-6-phosphate dehydrogenase message in liver and adipose tissue in rats. J Nutr. 2007;137:2616-21.

71. London E, Castonguay TW. Diet and the role of 11 beta-hydroxysteroid dehydrogenase-1 on obesity. J Nutr Biochem. 2009;20:485-93.

72. Woods SC, Seeley RJ, Rushing PA, D'Alessio D, Tso P. A controlled high-fat diet induces an obese syndrome in rats. J Nutr. 2003 Apr;133:1081-7.

73. Yang DH, Ye ZY, Jin B, He XJ, Zhang Q, Zhou WM, Xu WJ, Lu HX. Salvianolate inhibits cytokine gene expression in small intestine of cirrhotic rats. World J Gastroenterol. 2011 Apr 14;17:1903-9.

74. Kanarek RB, Orthen-Gambill N. Differential effects of sucrose, fructose and glucose on carbohydrate-induced obesity in rats. J Nutr. 1982 Aug;112:1546-54.

75. Collier G, Bolles R. Some determinants of intake of sucrose solutions. J Comp Physiol Psychol. 1968 Jun;65:379-83.

76. London E, Castonguay TW. High fructose diets increase 11betahydroxysteroid dehydrogenase type 1 in liver and visceral adipose in rats within 24-h exposure. Obesity (Silver Spring). 2011;19:925-32. 
77. Teff KL, Grudziak J, Townsend RR, Dunn TN, Grant RW, Adams SH, Keim NL, Cummings BP, Stanhope KL, Havel PJ. Endocrine and metabolic effects of consuming fructose- and glucose-sweetened beverages with meals in obese men and women: influence of insulin resistance on plasma triglyceride responses. J Clin Endocrinol Metab. 2009;94:1562-9.

78. Erickson AR, Enzenauer RJ, Nordstrom DM, Merenich JA. The prevalence of hypothyroidism in gout. Am J Med. 1994;97:231-4.

79. Johnson RJ, Perez-Pozo SE, Sautin YY, Manitius J, Sanchez-Lozada LG, Feig DI, Shafiu M, Segal M, Glassock RJ, et al. Hypothesis: could excessive fructose intake and uric acid cause type 2 diabetes? Endocr Rev. 2009;30:96-116.

80. Paxinos G, Watson C. The Rat Brain in Stereotaxic Coordinates. 2nd ed. San Diego: Academic Press, Harcourt Brace Jovanovich publishers; 1986. 